\title{
Labor Supply Decisions of Singaporean Cab Drivers
}

\author{
Sumit Agarwal (Department of Finance, National University of Singapore) \\ Mi Diao (Department of Real Estate, National University of Singapore) \\ Jessica Pan (Department of Economics, National University of Singapore) \\ Tien Foo Sing (Department of Real Estate, National University of Singapore)
}

May 8, 2013

\begin{abstract}
We use a unique dataset from the largest Singaporean cab company with over 520 million data points that tracks minute by minute of cabdrivers' work routine for a month to study the wage elasticity of labor supply. Our results show that both intraday and across days, cab drivers deviate from the neoclassical economic model and there is a reference level of income that they prefer to earn. Moreover, there are exogenous changes in intraday wages in Singapore. For instance at certain times and geographical locations the wages are higher due to peak period pricing. In these instances we find that across these threshold points cab drivers behave completely rationally and supply labor consistent with the neoclassical model.
\end{abstract}

Keywords: Labor Supply, Reference Dependent Preferences, Cab Drivers

JEL Classification Codes: J22, B49 


\section{Labor Supply Decisions of Singaporean Cab Drivers}

\section{Introduction}

Utility in the intertemporal/life-cycle labor supply model is measured over the lifetime consumption and lifetime wages. However, testing the life cycle model is difficult since, in principle, current wages depend on past and expected future wages. We face a dual problem of missing data and measurement errors in wages and labor supply. In a dynamic utility maximization problem, a transitory change in the wage rate will have a negligible impact on life-cycle wealth, so the implied wealth effect should be epsilon. Since the substitution effect of a wage change on hours worked is positive, a rise in the transitory wage should induce an increase in labor supply. So, a change in labor supply due to a transitory change in wages is an ideal test of the intertemporal/life cycle theory of labor supply. However, it is difficult to cleanly measure transitory changes in wages. The changes in wages are often not transitory, but serially correlated.

There is a large literature that studies the wage elasticity of labor supply. Using a panel dataset of male wages and labor supply decisions, the studies find the intertemporal elasticity of substitution ranging between -.07 to .45 . These results were estimated using a wide variety of data including aggregate data (Mankiw, Rotemberg and Summers, 1985), cohort data (Browning, Deaton and Irish, 1985), and panel data (Altonji, 1986). The unusually large standard errors surrounding the point estimates in these studies make is difficult to reject the null hypothesis that changes in life-cycle wages have no effect on work hours. This has motivated researchers to employ micro data to identify transitory changes in wages and test its impact on labor supply.

Camerer et. al., (1997) and Farber $(2005,2008)$ have looked at the micro data of New York City cabdrivers, they argue that cabdrivers are good subjects since their wages are transitory, and they can choose the number of hours to work each day. The data are less prone to measurement errors. However, these two studies find opposite results: Camerer et. al. (1997) find a negative wage elasticity implying that market labor supply decisions are set one day at a time. Cab drivers set a loose daily income target and quit working once the target is reached. They relate their results to the reference-dependence utility preferences. Farber (2005, 2008), however, supports the neoclassical model's argument that the labor supply (work hours of taxi drivers) is consistent with the existence of intertemporal substitution. Daily income effects are 
small. The decision to stop work at a particular point in a given day is primarily related to cumulative daily hours to that point rather than wages. The differences between these two studies lie mainly with the methodology and data. The contradictory findings have intensified the debate further with the introduction of a competing model of reference-dependence utility (Farber, 2008; Crawford and Meng, 2011).

In this paper, we revisit the same question but with a unique administrative dataset of over 520 million data points from the largest taxi company in Singapore for a period of one month (August 2010). We have the wage and labor supply information for all the taxi drivers at this company. A typical cab driver in Singapore works a 12 hours shift. All the drivers are Singaporeans, they rent their cabs from cab operators at a fixed rental rate of US $\$ 97.53$ $(\mathrm{S} \$ 120)^{1}$, and they incur a typical fuel cost of US\$40.64 (S\$50) a day. They typically earn S\$25 an hour, so they can break even in 7 hours. They can sub-lease the cab to a second driver and split the shift. We find that some driver do split the shift.

Additionally, we have exogenous variation in wages due to peak load pricing regulations that apply across time and space. Specifically, on the time dimension, 25\% surcharges are imposed on the fares during the peak hours from 6.00AM to 9.30AM and from 6.00PM to 11.59PM. After mid-night the surcharges increase to $50 \%$. If a cab driver takes passenger from the airport and designated places, there is an additional surcharge ranging US\$2.44 (S\$3.00) to US\$4.06 (S\$5.00). Moreover, there is also a premium for advanced booking of a taxi. All these variations give a clean identification of the changes in transitory wages. On the space dimension, leaving and entering the central business district (downtown of Singapore) entails additional charges. Finally, Singapore is an unusual country that has a total of 178 rainy days a year and a total annual precipitation of 2,075 millimetre ( $\mathrm{mm}$ ) (or a daily average of 11.66 $\mathrm{mm}$ ) in the year of 2010 (Source: Department of Statistics, Singapore). In our sample month of August 2010, there were 7 days with precipitation (sum of the precipitation at four major stations) of less than $2.54 \mathrm{~mm}$ (0.1 inch) and 8 days with precipitation of greater than 20.32 $\mathrm{mm}$ (0.8 inch).

Our dataset has several other advantages over the existing studies that look at this question using the data from the NYC cab drivers. They have wage information for less than 2000 trips for over 600 car drivers. We have data for 15000 cabs and 23000 drivers that span over 10

Based on the current May 8, 2013 exchange rate of S\$1 to US\$0.81, the Singapore dollar value is converted to US dollar value in this paper. The equivalent $\mathrm{S} \$$ dollar value is quoted alongside the US\$ term for easy reference. 
million trips. Unlike the data for the NYC cab drivers, which were hand-collected, we have GPS data that allows us to know the status of the cab minutes by minutes without any measurement error. We also know the exact location at any given time, which will allow us for our identification.

Previewing our results, we find that in a given 24 hour period, a typical cab driver has a passenger on board for over 6 hours, they are on break for close to 5 hours, they are free and looking for a passenger for 4 hours, and they are offline for another 8 hours. There is variation across days and by drivers. For instance, the average shift length for a given driver over the 30 days of our sample period is 10 hours with a standard deviation of 90 minutes. Conditional, on having a shift, they have a passenger on board for slightly over $50 \%$ of the time and the standard deviation is $10 \%$.

Next, we find that on average there is a negative relationship between wages and labor supply. The wage elasticity of labor supply is a kinked shape. For the most part the elasticity is zero, but after some time, it turns negative and the point estimate is -0.05 with a zero standard error. So, cab drivers do stop driving once they perceive to having earned a certain amount. We also test if the exogenous variation in wages has positive impact on labor supply elasticity. Our results show that cab drivers supply more labor on rainy days and during peak load pricing hours and locations. Our results support both the Camerer et. al. (1997) and the Farber (2005, and 2008) hypotheses.

The rest of the paper is organized as follows. In Section 2, we provide the institutional details of the cab company and the peak load pricing program in Singapore. In Section 3 and 4, give a brief literature review and data description respectively. In Section 5 we present the main empirical results. We present our conclusions in Section 6.

\section{The Cab Drivers and Operators in Singapore}

Singapore is an island state with a total land area of 715.8 square kilometer $\left(\mathrm{km}^{2}\right)$, which is slightly smaller than the city of New York (790 sq km). The total population of Singapore is estimated at 5.312 million as in 2012, which is made up of 3.285 million citizens, 0.533 million permanent residents, and the remainders are foreigners. Its population density of 7,421 persons $/ \mathrm{km}^{2}$ is about 30\% lower than that of the New York City, which is estimated at 10,436 persons $/ \mathrm{km}^{2}$ (based on population in the census 2011). Despite its small geographical 
size, it has one of the world's most extensive transportation networks across the island. Based on the statistics in the Land Transport Master Plan published by the Land Transport Authority $(\mathrm{LTA})^{2}$, Singapore has 5,128 cabs per one million of population (cab/million pop) as in 2007, which is three times larger than the 1,522 cabs/million pop in New York, and one and half times larger than the 3,285 cabs/million pop in London. Cab services are cheap in Singapore, where a $10 \mathrm{~km}$ trip will cost approximately US\$7.96 (S\$9.80), which is less than half of the US\$17.43 (S\$21.45) fare for the same trip taken in New York City. ${ }^{3}$

The cab market (or taxi market as it is called locally) in Singapore was liberalized in 2003 where barrier of entry was removed for new operator. Currently, there are seven operators ${ }^{4}$, both public and private firms, running a fleet of 28,210 cabs (Figure 1). The cab market is regulated, and only Singapore citizens with Taxi Driver's Vocational Licences (TDVLs) are allowed to work as cabdrivers in Singapore. There are a total of 95,764 TDVLs issued as in 2012. Cab drivers usually join an operator either as hirers or relief drivers. Hirers lease cabs directly from the operators, usually on six months or a year contract; whereas relief drivers make private arrangements with hirers to lease their cabs on selected shifts in a day. Different operators charge different daily rental rates in Singapore. The rates can range approximately from US\$52.83 (S\$65) to US\$97.53 (S\$120) per day depending on age, model, and fuel type of the cabs. Cabdrivers cover their on-the-road expenses, which include fuel costs, washing, parking and other miscellaneous expenses. A small number of cabdrivers own their cabs, and they constitute only not more than $1 \%$ of the total fleet. These cabs are recognized as yellowtop cabs, because of their unique yellow-top and black-body colours.

All cabs in Singapore are fitted with electronic meters. Cab fares are highly variables, which are made up of base fares and additional surcharges. The base fares include a flag-down fare of US\$2.44 (S\$3.00) to US\$4.06 (S\$5.00) for the first $1 \mathrm{~km}$, and a variable fare that are varied by distance travelled and waiting time. The distance-based fare is a step-up charge with US\$0.18 (S\$0.22) for every 400 meters in the first $1 \mathrm{~km}$ to $10 \mathrm{~km}$; and subsequently at US\$0.18 ( $\$ \$ 0.22$ ) for every 350 meters for the above $10 \mathrm{~km}$ distance. The waiting time fare is charged at US\$0.18 (S\$0.22) for every 45 seconds when cabs are caught in traffic jam.

2 LTA is a government agency entrusted with the responsibility of planning and managing public transport infrastructure and systems.

3 Fares are estimated based on a $10 \mathrm{~km}$ taxi trip, with 5 minutes waiting time, at off peak hours and with no surcharges. Exchange rate is based on July 2012 figures. (Source: LTA, Singapore)

$4 \quad$ The two largest cab operators, Comfort Taxi and City Cab, are owned by the Comfort Delgro Corporation Limited, a public firm listed on Singapore Exchange (SGX). They control 58\% of share of the cab market with a combined fleet of 16,299 cabs. 
Additional time-based surcharges and area-based surcharges are levied to regulate demands by commuters during peak hours and at selected locations. ${ }^{5}$ All cab operators in Singapore also offer current or advance booking services at a fee, which varies from US\$2.03 (S\$2.50) to US\$14.63 (S\$18.00) depending on the time of booking and the taxi type. Cab drivers will keep all the fare charged (flag-down fare, additional surcharges and booking fees), but they are required to pay a fee to operator for the booking services. Commuters, who travel into city at designated hours, are subject congestion charges, which are paid through the Electronic Road Pricing (ERP) readers in the cabs. The ERP charges payable on top of the cab fares are not retained by cabdrivers, but they are paid directly to the government. If you call for a taxi, a booking fee also applies. The total fare is shown on the taxi meter (Appendix 1).

\section{Literature Review}

The neo-classical theory of labor supply suggests that the labor supply should increase along with the increase in transitory wage (Lucas and Rapping, 1969). The reference-dependent utility theory of labor supply argues that the relation is negative (Kahneman and Tversky, 1991). A large poor of macro literature has tried to empirically test the two hypotheses, but the results are mixed, which show both positive and negative points estimates with large standard errors. Hence, the debate has moved into looking for micro level datasets. We will largely focus on the two papers by Camerer et. al. (1997) and Farber (2005, 2008), which exemplify the debate in the micro literature.

Camerer et.al (1997) is the first to study this question using the data of cabdrivers in New York City. Cabdrivers' wages are transitory as they can choose the number of hours to work each day. They gathered the data from the trip sheets, which were entered by hand by the drivers. They find negative wage elasticity, implying that labor supply decisions of the cab drivers are "one day at a time", and the cabdrivers set a loose daily income target and quit working once they reach that target.

Basically, they use the hours that drivers choose to work each day to represent labor supply, and explore their relationship between the average daily wages. There are three types of drivers in their sample: daily fleet drivers, lease-drivers who lease their cabs by week or month, and those who own a cab themselves, and their behaviors are slightly different. They

The variations in area-based additional surcharges will not be covered within the scope of the current paper. The effects will be studied in an accompanying paper that will examine whether cabdrivers are salient enough to exploit the information. 
first simply regress $\log$ (hours worked) on $\log$ (hourly wage) and other factors that also influence the hours worked, and find that the elasticities are negative, but the magnitude depend on whether the driver fixed effects are included in the model. Since hours worked may include recording errors, and the average hourly wage is calculated out of hours worked, there might be measurement errors which lead to the negative elasticity. To address this, they use summary statistics of the distribution of hourly wages of other drivers that drove on the same day and shift as IV for a driver's wage, and find that the elasticities are even more negative and significantly different from 0 . Then they explore the elasticities of different experience group, and find that the low-experience elasticities are strongly negative, which are general near -1 , and those of the high-experienced drivers are much higher. Additionally, they find that if drivers can follow a simple strategy---driving a fixed hour every day, they may get higher income and leisure utility. To explain their findings, they think one possible way is that cabdrivers take a one-day horizon, set a target/target range, and quit when the target is reached. In the last part of their paper, they rule out several alternative explanations.

They rule our liquidity constraint explanation because drivers in their samples are actually not constrained. The break explanation which indicates that some time without customers can be considered as leisure rather than work might account for the negative elasticity also does not work because they have moved out long breaks, and it cannot explain the increased elasticities of experienced drivers. Also, the results cannot be attributed to increasing disutility of effort because most drivers thought searching passengers were even more tiring than working for the same time during the survey. Lastly, there might be unobserved factors which affect drivers' decisions about whether to work at all, as well as their hour decisions, but they think this issue is not severe since they have included the driver fixed effect in their regression, and many drivers report they have regular schedules.

Farber (2005) supports the neoclassical model using the same data of New York City cabdrivers. He argues that the labor supply of taxi drivers is consistent with the existence of intertemporal substitution, daily income effects are small, and the decision to stop work at a particular point on a given day is primarily related to cumulative daily hours to that point rather than the wage. He also claims that the different results from his paper and the paper of Camerer et.al (1997) mainly due to important differences in empirical methods and conceptual frameworks. Different from Camerer et.al., Faber's survey suggests that drivers do not consciously behave as though they are target earners 
He critiques the model of Camerer et.al. that their model relies on there being significant exogenous transitory day-to-day variation in the average wage, which is not the case, and that there might be day-specific factors affecting both the wage and hours conditional on the wage of all drivers, thus the IV they used cannot purge their estimation; and another econometrical problem is that they are not able to use the calendar dates on which there is only one driver. In the empirical part, he calculates the hourly wage in a different way, using the trip-level fare and time information: the hourly wage was computed by dividing each shift into minutes and assigning a "minute wage" to each minute, and then sum up the minute wages during that hour to get the hourly wage. He finds that the autocorrelations of hourly wages are very small, suggesting there is no important transitory daily variation in the hourly wage. Using the probit optimal stopping model, he finds that after accounting for inter-driver differences, the probability of quitting is not significantly related to income but is significantly related to total hours. His conclusion is that hours of work are a central determinant of the stopping decision but daily income is not related to the stopping decision. To further investigate the importance of driver heterogeneity, he estimates separate stopping models for six drivers, and finds that the stopping rules for these six individuals are also consistent with the neoclassical model of labor supply rather than the target earnings model.

Interestingly, Farber (2008), starts to somewhat believe in the reference-dependent preferences, and provides some evidence for it using the same data as in the previous paper. In this paper, he develops an empirical model of daily labor supply that incorporates referencedependent preferences but does not require that the reference level of income be observed or defined in advance, since the identification is a difficult work. He implements referencedependent preferences by allowing the marginal utility of income to be higher at income levels below the reference level than at income levels above the reference level, thus the utility function is continuous everywhere, but marginal utility is discontinuous at the reference level. Using his data, he finds that the continuation probability is close to zero once the reference income level is reached, regardless of when in the shift is reached, which would be a strong evidence of the importance of reference-dependent preferences. There are four types of evidence consistent with reference dependent preferences paying an important role in determining daily labor supply: (1) the continuation probability decreases dramatically when the reference income level is reached; (2) large estimated within-driver inter-day variance in the reference income level implies that there is little consistency in a driver's reference income level day to day; (3) there is a strong positive correlation between both average 
income and average hours across shifts for a given driver and that driver's estimated mean reference income level; (4) the probability that reference income level is attained on a given shift is relatively low. However, he raises a puzzle at the end of this paper: the data show that drivers seem to generally stop before the reference income level is reached, and show more smoothness in the relationship between income and the continuation and stopping probabilities than seems consistent with an important role for reference-dependent preferences; additionally, the relatively large unexplained within-driver variation in income across shifts also belies an important role for daily reference dependence.

Fehr and Goette (2007) conduct a field experiment on bicycle messengers, finding a large positive elasticity of overall labor supply and an even larger elasticity of hours, which implies a negative elasticity of effort per hour. Zurich et.al. (2004) gives a review of a bunch of works on this issue, and claim that they are consistent with a model of reference-dependent preferences (RDP) exhibiting loss aversion and diminishing sensitivity.

\section{Data Description and Experiment Design}

\subsection{Real time trip data from global positioning system (GPS) enabled cabs in Singapore}

The previous studies by Camerer et. al. (1997), Farber (2005) used mainly trip sheets data recorded by cabdrivers, which were provided by different cab companies in New York City. Farber (2008) and Crawford and Meng (2011) use the same set of data collected by Farber (2005) in their test of reference-dependent preference in cabdriver labor supply. The largest of Camerer et. al. (1997) sample consists of 484 cabdrivers with 1,044 recorded trips; whereas in Farber (2005), 584 trips were extracted from the trip sheets of a smaller sample of 21 cabdrivers. The time periods were also different in the two samples, where Camerer et. al. (1997) trip sheets were recorded between 1988 and 1994, and the trip sheets in Farber (2005) were recorded between 1999 and 2001.

In 1999, the cab operators in Singapore started installing GPS satellite-based tracking and dispatching system. ${ }^{6}$ In the same year, the LTA also developed an automatic data collection system, known as the "TraffiScan" system, to collect traffic speed data from a fleet of cabs on the road. In 2006, an enhanced e-TrafficScan system was implemented after the cab operators

6 “World-first satellite tracking, booking system for Tibs taxis,” The Straits Times, November 24, 1995. 
have upgraded the wireless communication in cabs to a new high bandwidth General Packet Radio Services (GRPS). The e-TrafficScan system enables real time speed data collection from cabs on the road at an interval of less than 3 minutes. The real time data for the full month of August 2010 were collected from two of the biggest cab operators in Singapore for this study. The two cab operators currently run a combined fleet of 16,299 cabs as in 2012, which cover $58 \%$ of the market share in Singapore by the number of cabs.

The real time logs contain 16,793,501 data points from 15,406 cabs each day on average. A point is a row of GPS trace data of a cab in the real time logs, which include the fields such as $\mathrm{XY}$ location, time stamped, speed, status, plate number and driver ID of the cab at that point in time. A time interval, which is less than 3 minutes, is computed by the difference in times recorded between two consecutive points. Based on the points, we generate data on trips. The first point in the log of a cab is the start time of a trip identified by a specific status, and the end time of a trip is identified by the last point in a series of consecutive points identified by the same status. A trip indexed against a status, a driver and a cab is defined by the difference in times between the last point and the first point, or the equivalent of cumulative consecutive intervals of the first to the last points.

Comparison of the Cabdriver data used in the three studies:

\begin{tabular}{|c|c|c|c|}
\hline & This paper (2013) & Camerer et al (1997) & Farber $(2005,2008)$ \\
\hline City & Singapore & New York City & New York City \\
\hline Data source & $\begin{array}{l}\text { GPS-enabled electronic } \\
\text { data }\end{array}$ & Trip sheets & Trip sheets \\
\hline \multirow[t]{2}{*}{ Source } & $\begin{array}{l}2 \text { Cab operators in } \\
\text { Singapore }\end{array}$ & $\begin{array}{l}\text { 1)A fleet company in New } \\
\text { York City (TRIP) }\end{array}$ & $\begin{array}{l}1 \text { taxing leasing } \\
\text { company in New York } \\
\text { City }\end{array}$ \\
\hline & & $\begin{array}{l}\text { 2) Two data sets from } \\
\text { New York City Taxi and } \\
\text { Limousine Commission } \\
\text { (TLC1 and TLC2) }\end{array}$ & \\
\hline $\begin{array}{l}\text { Sample } \\
\text { period }\end{array}$ & Aug-2010 & $\begin{array}{l}\text { 1) TRIP: April 24, } 1994 \text { to } \\
\text { May 14, } 1994 \\
\text { 2) TLC1: October 29, } \\
\text { 1990 to November 5, } 1990 \\
\text { 3) TLC2: November 1 - 3, } \\
\text { 1988 }\end{array}$ & $\begin{array}{l}\text { 1) June } 1999 \text { to May } \\
\text { 2000 } \\
\text { 2) June } 2000 \text { to May } \\
\text { 2001 }\end{array}$ \\
\hline \multirow{3}{*}{$\begin{array}{l}\text { Number of } \\
\text { sample trips } \\
\text { (screened) }\end{array}$} & 15,406 average per day & 1) Trip: 70 & 584 \\
\hline & $\begin{array}{l}\text { 520,598,520 point } \\
\text { observations }\end{array}$ & 2) TLC1: 1044 & \\
\hline & & 3) TLC2: 712 & \\
\hline
\end{tabular}




\subsection{Summary Statistics}

We adopt a systematic screen process to remove abnormal shifts and shifts with incomplete information from our sample data prior to the analyses. We first remove data with incomplete shifts, which either start before 0030 hours on the first day (August 01, 2010), or end after 2330 hours on the last day (August 31, 2010). Other screens include removing shifts that have continuous working trips with one single status of longer than 2 hours; that have 10 or more short POB trips of less than 2 minutes; and that are shorter than 3 hours or longer than 16 hours. We also screen out some cases where multiple shifts are made by the same drivers within a day, and/or multiple shifts by more than 3 drivers within a day.

After the screens, the one-month real time logs in August 2010 yield a cumulative number of over 520 million points. The points are sorted day-by-day using the identification numbers (IDs) of a total of 477,577 cabs (average of 15,406 cabs each day) and 779,417 drivers (average of 25,142 cabdrivers each day including relief drivers who lease the cab from the hirers) over the one month sample period. Based on the day-cab sorted observations, we generate trip data for each day based on different vehicle status indications, such as passenger on board (POB), BREAK, FREE, OFFLINE, PAYMENT, and others (See Table 2 for descriptions). The multiple trips in each day are added up for each driver to give the day-shift data for both single-shift cabs and two-shift cabs. Table 1 shows the daily summary statistics by different status. More real time points were recorded in the mid-weeks (Wednesdays and Thursdays); whereas the real time points were relatively smaller in the week-end logs (Saturday and Sunday). The highest number of points was recorded on August 19, 2010 (Thursday). August 14, 2010 (Saturday) recorded the largest number of 15,686 cabs on the road, and August 13, 2010 (Friday) was the day with the largest number of 25,767 cabdrivers on the road.

\section{[Insert Table 1 here]}

Based on the monthly aggregate level and daily average trip data in Table 2, we analyze the activities of cabdrivers by their vehicle status. Based on the 11 status identified each day in the real time logs (a total of 1,440 minutes or 24 hours), the "passenger on board” (POB) takes up $27.71 \%$ of the time on the road, which is equivalent to a monthly cumulative time interval of 190,637,213 minutes, or 399 minutes per day on average. The cabdrivers' fare generating services (POB), which measure their output, average at 6.65 hours each day (24 hours). They also spent on average about 304 minutes (5.07 hours) searching for commuters as indicated by 
"FREE" status, which took up $21.11 \%$ of their time each day. If we group the "working” activities as indicated by status 1 to 6 as in Table 2, (FREE, POB, ONCALL, ARRIVED, NOSHOW and PAYMENT), and the remainder as "non-working” activities of a typical cabdriver, a cab was used on average $51.39 \%$ of the time each day on the road. ${ }^{7}$ The productive output of cabdrivers could be further expanded if the balance of $48.61 \%$ of the time each day could be utilized to generate fare services. ${ }^{8}$ The distributions of the activities (status) of cabdrivers at the monthly aggregate level are consistent with those daily activities observed for average cabdrivers.

[Insert Table 2 here]

\subsection{Inter-day/Intra-day variations in activities}

We plot the distributions of cabs by time (starting at 0030 hours and ending at 2330 hours each day) and by the cab activity status for the full month of August 2010 (Figure 1), also the distributions by the week from August 15 to 21, 2010 (Figure 2). The vertical axis measures the frequency distributions of the cabdriver number; whereas, the horizontal axis measures the time by minutes in an ordinal scale covering the full one month period starting from 1 August, 2010, and the one week period starting on August 15, 2010. The two charts show recurrence of inter-day patterns across the two periods. Four major activities that are POB (purple line), OFFLINE (light blue line), FREE (light green line) and BREAK (orange line) dominate by the frequency of cabs in the two figures. The OFFLINE (green line) activity always peak preceding the POB activities, which indicates either change of shift or stopping for the day by the sample cabdrivers.

\section{[Insert Figures 1 and 2 here]}

From the weekly activities for the periods August 15 to 21, 2010, we further zoom into dayby-the-week (inter-day) variations in the cab activities by plotting the distributions for three selected days, which include a Saturday (August 15, 2010), a Wednesday (August 18, 2010)

Despite the high cab to population ratio of 5.2 cabs per 1000 population vis-à-vis 1.5 cabs per 1000 population in New York, the cabdrivers in Singapore drive only about 9 to 10 hours a day, compared with 18 hours clocked by New York City cabdrivers. Read the article by Tan, Christopher, "Will new taxi rules boost availability?” Straits Times, November 26, 2012.

8 LTA implemented new minimum taxi availability (TA) standards with effect from 1 January 2013 to ensure that taxi services are better utilized and made more available on the road to serve commuters especially during the peak hours. The TA standards require $70 \%$ of the taxi drivers to drive at least $250 \mathrm{~km}$ per day, and the cab operators must ensure that $70 \%$ of their fleets of taxis are on the road during the morning and evening peak hours (Source: LTA). 
and a Sunday (August 21, 2010). Given that the X-axis represents the time of a day starting from 0000 hours and ending at 2359 hours (Figure 3), the rightward skewed blue lines, of the majority of the cabs (above 4000) are in "OFFLINE" status in the first 6 hours (around 6.00AM on Wednesday) to 10 hours (10AM on Sunday). We observe the number of “OFFLINE” cabs peaks at around 5 hours (300 minutes), indicating a large number of cabs off the road at around 5.00AM for all the three subject days. We also find a smaller second peak with around 5,000 cabs in the OFFLINE status at the end of Sunday (1440 minutes).

As the total number of cabs is relatively constant in a day, the number of cabs "working" on the road (POB, FREE and other working status) is inversely related to the cabs in an “OFFLINE” status. Most of the cabdrivers work between 12 hours on Sunday and 18 hours in weekdays. In the next section, we will further analyze the work hours of individual cabdrivers (i.e. separate 2 shift cabs by drivers) by further decomposing the inter-day data into intra-day shift data. The purple lines show that in a weekday (August 18, 2010), the peak in the number of cabs in fare service (POB status), a proxy of wage (at individual cabdriver level)/demand (at aggregate level), occurs at around 8.00AM (500 minutes), and subsequently the second smaller peak was found around 8.00PM (1200 minutes). The distributions of cabdrivers with passengers on board (demand) are similar in the two days on Saturday and Sunday, but the frequency of cabs with POB status is lower on Sunday. We also observe that the demand for cabs (POB) is higher during the periods from 1.00PM to 3.00PM on Saturday than the same periods on weekdays. The results clearly show significant variations in inter-day demands (and) and also wage rates of cabdrivers in different days in a week.

\section{[Insert Figure 3 here]}

Next, we analyze intra-day variations in cab activities by plotting activities of a randomly selected 5000 cabs by time (in minutes) in a day. Each line on the Figure 4 represents the activities (status) of one sample cab in a day starting from 0000 hours to 2399 hours. We observe two clear patterns of intra-day activities, where a lull period as indicated by OFFLINE and FREE status was observed in the earlier hours between around 3.00PM to 7.30PM, and the busy period (blue lines) where most cabs were in POB status in the period from 8.00AM to 10.30PM.

[Insert Figure 4 here] 


\subsection{Inter-day Demand and Supply Elasticity for Cab}

Based on the real time data, “FREE”, “POB”, “ONCALL”, “ARRIVED”, “NOSHOW “and "PAYMENT" are identified as the "working" status for cabs each day. The POB status indicates the fare services provided by cabs. We compute the cumulative frequency distributions of cabs for "working” status and fare paying services (POB) by minutes each day. The ratio of the cumulative number of cabs in POB status over the cumulative number of cabs in "working” status is computed by one minute interval. This ratio, which is denoted as "UTIL", measures the demand (utilization) for cabs on the road by minutes. A high ratio that is close to unity also implies a high productivity output (efficiency) of cabdrivers on the road. In contrast, a high utilization rate will have negative impact on the service delivery ratio, because we may expect longer wait time to flag down a cab during the peak hours. The ratio is an indicator that could be used to monitor the "taxi availability" standard implemented by the regulator (LTA) with effect from 1 January 2013.

Figure 5 plots cumulative numbers of cabs in both "working” (inclusive of POB) (a proxy of cab supply) and POB (a proxy of cab demand) status, and the ratio of POB cabs over working cabs by minute for the month of August 2010, starting on August 1, 2010, which is Sunday. We observe the recurrent peak-trough patterns in both working cabs and POB cabs on the road day-by-day. The supply (worked interval) and demand (POB interval) are higher during the weekdays relative to Saturday and Sunday. The twin lull periods in the first weeks of August as shown in the Figure 5 were coincided with Sunday (August 8, 2010) and the National Day public holiday in Singapore (August, 9, 2010, Monday). We plot the day-by-day cumulative frequency distributions for cabs in working and POB status, and the cab utilization rate for the week of August 15 to 21, 2010 in Figure 6. We find that cabdriver labor supply (worked intervals) is low on Sunday, and the corresponding POB cabs (the cab demand indicator) are also low on Sunday vis-à-vis other days in the week. The results seem to imply that the cabdriver labor supply is highly correlated with the demand, which as a result, the inter-day utilization rate (an indicator of cab availability standard) on Sunday is not significantly lower than in other days in a week.

\section{[Insert Figures 5 and 6 here]}

Figure 7 shows inter-day variations of cabdrivers' working activities in three days in August 2010, which include a Sunday (August 15, 2010), a Wednesday (August 18, 2010) and a 
Saturday (August 21, 2010). We find some variations in cab demand for the three days. In the weekdays, the cab demand peaks around 8.30AM and 8.30PM, whereas the morning peak was less significant on Saturday, where a high demand is observed in the evening periods around 8.30PM. For Sunday, the high cab demand occurs in the mid-day around 1.30PM to 3.30PM. As the supply of cabs (working status) is highly elastic, we observe the utilization ratio of cabs to correlate closely with the cabdriver labor supply (working status) throughout the day. The inter-day variations in the utilization are also observed, where we saw higher utilization rate of cabs on Sunday, despite the lower labor supply of cabdrivers on the day vis-à-vis other days of the week.

\section{[Insert Figure 7 here]}

The inter-day analysis based on cumulative cab frequency in the previous section explains labor supply elasticity in response to cab demand. The data do not differentiate cabs operated by single driver or two drivers, and they also do not directly measure of worked hours by individual cabdrivers. We need to go down to inter-shift (shift-by-shift) level data by indexing the activities (working and fare services) for each cabdriver (by shift) each day in testing for labor supply elasticity of income.

\section{5. $\quad$ Shift-level Work hours and Wage Measures}

This study aims to empirically test the target earning hypothesis of Camerer et. al. (1997) that predicts a negative labor supply elasticity against Farber's (2005 and 2008) neoclassical view that argues for positive inter-temporal lobour supply elasticity. Like the two earlier studies, we need to measure the worked hours and wage (income) of cabdrivers. Camerer et. al. (1997) and Farber (2005 and 2008) both used hand-recorded trip sheets data from cabdrivers in New York City; whereas, we have access to very high frequency real-time data collected through GPS enabled system installed in Singapore’s cabs. In Camerer et. al. (1997) and Farber (2005 and 2008), hours worked per day are defined by difference between trip start time (first passengers is picked) and trip end time (when the last passenger is dropped). The worked hours are truncated if cabdrivers start work before the first passenger is picked up, and/or if they do not stop immediately after the last passenger is dropped off. We, however, used the GPS-based data to identify the worked hours of Singapore cabs through the status recorded in 
the real time logs of each cab minute-by-minute. The high frequency data are more accurate and reliable in tracking the worked hours of cabdrivers. ${ }^{9}$

The data are not without limitations. The data do not capture the fare amounts collected by cabdrivers for each POB trip. As our cabdrivers' data were obtained from two related cab operators, where the same rate for flag-down, distance-based and waiting time fares are metered and charged, we could assume the cab fares to be correlated with POB time intervals for each trip. ${ }^{10}$ The ratio of aggregate POB time intervals over total worked intervals (“working status”) per shift is thus used to define wage rate (income) of individual cabdrivers in each working shift.

For the tests of the worked hours and wage relationships, we need to derive the shift-level data for each driver, such that the behavior of hirers (main cabdrivers) can be separated by relief drivers especially for the two-shift cabs. We define a shift as a set of consecutive trips with different status by the same driver of the same cab. The shift starting time is the first point in the real time log of a cabdriver, and his shift ending time is identified by the last point of the last working trip in the log. The starting and ending shifts are separated by a non-working break of at least 6 hours in the case of a single-shift cabdriver (hirer) (i.e. a single shift cabdriver could have driven by up to a maximum of 18 hours a day); or by the start of the new shift by a relief cabdriver if a cab is driven in two shifts in a day. The worked hour, denoted as T_SHIFT, is computed as the time intervals (in minutes) between the starting shift time and ending shift time.

Figure 8 plots the activities of 5000 randomly selected cabdrivers from the sample against the worked interval (T_SHIFT) on the X-axis as if all of them start work at the same time. The black colored portion of the Figure represents the offline status, which indicates that majority of the cabdrivers stop works after approximately 10 hours (600 minutes). Some cabdrivers stop work earlier; whereas few hard-working ones stretch their worked hours up to 16.7 hours (1000 minutes). The data show significant variations in the work intervals of cabdrivers.

[Insert Figure 8 here]

\footnotetext{
9 We can also locate their trip route from the data. The information is used in an accompanying paper attempting to study whether cabdrivers are salient in exploiting the area-based fare variations.

10 Additional surcharges are levied for trips starting from selected location such as airports, city area, Marina Bay Sands etc., but the location data are not used in this study. We assume the cab fares to be exogenously determined by interval and distance travelled.
} 
We next analyze the properties of shift-level data of average cab drivers in terms of shiftdistributions (Figure 9), shift-starting time (Figure 10) and shift-ending time (Figure 11). Figure 9 plots distributions of aggregate shifts day-by-day for the full sample month in August 2010. The results are consistent with earlier cab-driver labor supply in Figure 5, which show that more than 20,000 shifts were made by cabdrivers in total during the weekdays. The shift numbers were relatively lower on Sunday and public holiday (August 9, 2010). By denoting the X-axis as the clock time (Figures 10 and 11), we observe there are two peaks in the days where cabdrivers start their shift. Majority of first (morning) shift drivers start work at 6.00AM and end the shift at 4.00PM, which work up to be about 10- hours work per day. Some of single-shift cabdrivers may stretch their worked hours beyond 10 hours as indicated by a relative uniform distribution of shift-ending from 7.00PM to 11.59PM. For the second (night) shift drivers, majority of them start their works at 5.00PM, and end their shift between 1.00AM to 5.00AM. Few night-shift cabdrivers will go beyond 6.00AM, when the changing shift is usually arranged with the hirers (main drivers). The work hours of the night-shift drivers seem to be shorter relative to the day-shift drivers.

\section{[Insert Figures 9, 10 and 11 here]}

Next, we analyze the worked hours as measured by the length (in minutes) of shift by each drivers. Figure 12 shows the distributions of shift length by the full sample of 637,255 shifts recorded in the full month of August 2010. Figure 13 and 14 shows the worked hours characteristics of active cabdrivers, which are identified in our paper as those who drive at least 20 shifts in the month of August 2010. We exclude "leisure" cabdrivers, who are usually part-time relief drivers working only on selected days in a month, to minimize distortion in worked hours statistic. Figure 12 shows a bell-shaped distribution of an average cabdriver works 572.5 minutes (9.54 hours) in one shift. The shift intervals of $93.7 \%$ of the cabdrivers (or 597,074 cabdrivers) are bounded within the range of between 3 hours and 16 hours. The shift intervals of active cabdrivers are normally distributed as in Figure 13, and but distributions of standard deviations of shift interval skew to the right (Figure 14). The mean standard deviations of approximately 90 minutes (1.5 hours) implies that average difference in worked hours of cabdrivers will not likely to go beyond 12 hours (i.e. 9.54 hours +1.5 hours).

\section{[Insert Figures 12, 13 and 14 here]}

Using the POB interval over the total "working” hours in each shift as a proxy of wage rate for cabdrivers, denoted as "RATIO", we found that wage rates of active cabdrivers are skewed 
slightly to the left (Figure 15), and the standard deviations of the wage rate are slightly skewed to the right (Figure 16). A "RATIO" has a value ranging from zero to unity, where a value that is close to unity means that cabdrivers are highly productive and earn above average wage rate in a shift; whereas a "RATIO" on the left-hand tailed of the scale, i.e. close to zero, means relative low wage rate for a cabdriver in a shift. A The average POB trips constitute about slightly less than 0.5 of the working trip in each shift for active cabdrivers (who drive 20 shifts or more in a month), and variations in wage rage ("RATIO”) are small at an average of 0.075 .

[Insert Figures 15 and 16 here]

\section{Tests of Cabdriver Labor Supply Elasticity}

In this section, we test the target earning hypothesis versus the inter-temporal lalour substitution hypothesis. We first do a pair-wise curve fitting of labor supply (T_SHIFT) and wage rate (RATIO). Next, structural multivariate models of labor supply on wage rate and other covariates are estimated. 556,490 shift-level observations are used in both pairwise curve fitting and multivariable regressions.

\subsection{Pairwise Relationships between worked hours and wage rate}

We use local polynomial regressions to fit the worked hours (T_Shift) and wage rate (RATIO) data of all the 556,490 shift level observations, and the scatter plots and local polynomial curves are shown in Figure 17. The downward curves could not reject the negative elasticity in cabdriver labor supply hypothesis of Camerer et. al. (1997), but the relationships are nonlinear. The curve shows an initial positive income effects when the wage rate (RATIO) is less than 0.5 , and the income effect is positive on worked hours. The result is consistent with the split sample model of Crawford and Meng (2011). However, their results found no significant relationships between worked hours and wage, when income exceeds the target. In our nonlinear (polynomial) fitted curves, however, we found that the inter-temporal labor supply elasticity is negative, if the wage rate exceeds 0.5 .

\section{[Insert Figure 17 here]}

Figure 18 shows the income-wage relationships conditional of differences between singleshift cabdrivers and two-shift drivers. The curvature (second derivative) is larger for singleshift cabdrivers (Figure 18a), which imply that single-shift drivers are more sensitive to the 
wage rate changes when they decide to stop works for the shift. The labor elasticity of income effects of the two-shift drivers are smaller (Figure 18b), and a flatter curve is observed, if we only use the weekday shifts in our plots (Figure 18d). The rainy days effects are also significant, where we observed more elasticity in labor supply in high rain days (Figure 19a) compared to low rain days (Figure 19b).

[Insert Figures 18 and 19 here]

\subsection{Structural models of cabdriver labor supply and wage rate}

Like Camerer al. et. (1997), we estimate the cabdriver labor supply as a function of wage rate and other controlled variables in an OLS framework as follows:

$$
\text { T_SHIFT } \mathrm{i}_{\mathrm{i}, \mathrm{t}}=\alpha_{\mathrm{i}}+\delta_{\mathrm{i}} * \mathrm{RATIO}+\mathbf{X}_{\mathrm{i}, \mathrm{t}} \boldsymbol{\beta}_{\mathbf{i}}+\xi_{\mathrm{i}}
$$

Where T_SHIFT denotes the worked interval (in minutes) of cabdriver $i$ in shift $t$ of a day, RATIO is a wage rate, which is represented by the fares paying trip (POB time) divided by the total working intervals ( $\left.\mathrm{T} \_S H I F T\right)$ in each shift t, i.e. [RATIO $=$ POB/T_SHIFT], and $\mathrm{X}_{\mathrm{i}, \mathrm{t}}$ is a vector of exogenous factors that affect cabdriver labor supply. We control for heterogeneity using day dummies to control for lull periods on "Saturday", "Sunday" and “National Day" (August 9, 2010). We control heterogeneity in shifts using a "NIGHT" dummy, which has a value of 1 , if a cabdriver start the shift after 3.00PM; and 0 otherwise; and a "Is2Driver", which has a value of 1 for a two-shift cab, i.e a cab that is shared by 2 drivers; and 0 otherwise. Like in Camerer et. al. (1997) and Farber (2005 and 2008), we control the experience of cabdriver based on cabdrivers' ID number (which is referred to as hack numbers in Camerer et. al. (1997)), we rank cabdrivers by their ID and sort them into two groups, where experienced cabdrivers will have ID numbers that are smaller than the first quartile cut-off. We also control for raining day effects by including two weather dummies controlling days with the highest precipitation (i.e. "Rain_high" =1, if rail fall in a day is more than 0.8 inch) and days with the lowest precipitation (i.e. "Rain_low" = 1, if rail fall in a day is less than 0.1 inch).

The OLS regressions results and the corresponding log-version of the models (log-T_SHIFT against log-RATIO) are summarized in Table 3. Our results in both OLS and the log-OLS models show that the coefficients on wage rates both in absolute value models (Model 1: 168.620 and Model 3: -166.143) and log-value models (Model 2: -0.059 and Model 4: -0.057) are negative and significantly different from zero. The results support Camerer et. al. (1997) 
findings that there is a significant but negative labor supply elasticity of wage in cabdrivers, where we find that cabdrivers stop works after the target income is reached. However, compared to the estimates of Camerer et. al. (1997) of -3.55 to -5.01 , our estimates of the wage elasticity of cabdriver supply is relatively smaller at -0.057 .

[Insert Table 3 here]

As Camerer et. al. (1997) and Farber (2005 and 2008) pointed out, using the wage rate (T_SHIFT), which is also the dependent variable in the model, as the denominator of the wage rate measure could potentially cause downward (negative) biases to the estimates of the wage elasticity on labor supply $\left(\delta_{\mathrm{i}}\right)$, if any measurement errors of worked hours occur. As our data are real time data recorded with precision by GPS-enabled technology, we expect measurement errors to be marginal compared to the hand-collected trip sheet data in the two earlier studies on New York cabdrivers. We control for potential biases by adding the fixed cabdriver effects to the OLS and log-OLS models in Table 4. The results show that the coefficients on wage are still significant and negative. The coefficient in the OLS model increases to -156.000 after controlling for fixed cabdriver effects. In the log-labor supply models, we show that the wage elasticity of labor supply is still negative and significant, but the elasticity value decreases to -0.061 . Based on the total working hours, we sort cabdrivers into a "leisure" group $\left(1^{\text {st }}\right.$ quartile $)$ and a "hard-working” group $\left(4^{\text {th }}\right.$ quartile $)$ and rerun the fixed-effect models for these two groups of cabdrivers. The results in columns 3 and 4 of Table 4 show that for cabdrivers who work short hours in a shift ("leisure" group), the wage elasticity is higher at -0.085 compared to -0.047 elasticity of wage on labor supply of cabdrivers who work long hours ("hard-working” group). In other words, cabdrivers who work short shift in a day are more sensitive to target earnings relative to cabdrivers who work longer hours in each shift. The earning target is high in the earlier hours of a shift, the "leisure" cabdrivers are more likely to stop works earlier, and the results are consistent with the asymmetric target earners model of Crawford and Meng (2011).

[Insert Table 4 here]

\subsection{Heterogeneity in Cabdrivers' Labor Supply Elasticity}

Like Camerer et. al. (1997), we sort cabdrivers based on the ID in ascending order with the earlier number in the first quartile as an identification of experienced cabdrivers, and the cabdrivers whose ID are ranked in the $4^{\text {th }}$ quartile are identified as new (relatively 
inexperienced) cabdrivers. We run the two fixed effect models, and the results are summarized in Table 5. We found that experienced cabdrivers are more sensitive to the wage rate (POB/Worked hours) effects and they stop works earlier when they reach their target earnings for the days. Whereas the negative elasticity for newer cabdrivers is smaller, the coefficient is still statistically significant at less than $1 \%$ level.

[Insert Table 5 here]

We also examine the impact of the shift constraint imposed on 2-shift cabdrivers, where they are subject to the worked hour limit of not more than 12 hours a day, because they are required to transfer their cabs to their co-cabdrivers (relief drivers) at the time agreed between them. The results as shown in Table 5 show that the 2-shift cabdrivers are less sensitive to the income (wage) effects. Compared to single-shift cabdrivers (2-shift), cabdrivers facing shifttime constraint are more likely to drive longer hours and less responsive to income effects. However, for cabdrivers who do not co-share the cabs with relieve cabdrivers, they appear to be the stronger target earners and will stop works earlier, if they achieve their income target. The single-shift cabdrivers (1-shift) are more sensitive to income effects. The negatively income elasticity to supply of the single-shift drivers is higher than the cabdrivers who face the shift-hour constraints (12-hours).

In the last two columns of Table 5, we test the impact of wage (fare) variations on the income elasticity of labor supply of cabdrivers. We use the peak periods between 6.00PM and 9.30AM to identify wage variations, where a peak period surcharge of $25 \%$ (6.00PM to 11.59PM and 6.00AM to 9.30AM) and a midnight surcharge of 50\% (12.00midnight to 5.59AM) are imposed on the cab metered fares. We found that that cabdrivers' income elasticity (-0.05442) during the periods when the peak hours and midnight surcharges are imposed is lower compared to cabdrivers in regular hours (-0.06727). Cabdrivers are "weak" target earners during periods when wage is high (periods with surcharges).

\subsection{Serial correlations in total work hours}

In the neo-classical model, variations in income should be uncorrelated within a day and across day, such that these changes in the drivers' income should have no explanatory effects on their work hours in a day or a shift. Therefore, constancy in work hours of cabdrivers should be expected in the neo-classical model. We test the constancy hypothesis using a structural model that regresses the work hours/shift by driver/day against the lagged effort 
levels indicators, represented by the wage ("RATIO) and the income ("POB”) variables. For the lag effects, we test the day-by-day effects using the previous day effort levels as the lagged control variable, and also test the beginning of the month effects, where the first week of the month effort levels (August 1-7, 2010) are used as the control variables, and the last week of the month effort level (August 22-28, 2010) are used as the response variables. The models will also control for variations related to Weekend days (Saturday and Sunday), raining day, and drivers' heterogeneity. For the day-by-day regression, the National Day effect on August 9, 2010 and other day fixed effects are controlled.

Table 6 summarizes the regression results. The work hours /shift in the day-by-day model are negatively correlated with the previous day income, as represented by the log of one-day lagged "POB", and log of wage, as represented by log "RATIO". The work hours/shift, however, is positive correlated with the previous day log-RATIO variable. The negative coefficient on the current wage (Log-“RATIO) variable is consistent with the hypothesis of a negative elasticity of labor supply of cabdrivers of Camerer et. al. (1997). The constancy in the work hours/shift within a day is rejected by the results, as the previous day earnings (income) significantly reduce the work hours in current shift of cabdrivers. The high wage (log-ratio) in the previous, however, encourages cabdrivers to work longer hours in current shift.

\section{[Insert Table 6 here]}

For the end-of-the-month work-hours model, we found that the negative elasticity supply of cabdrivers is not rejected by the significant and negative coefficient on the current log"RATIO" variable. On the coefficients on the first months wage (the first month log-RATIO) and income (the first month log-POB), the signs of the two coefficients were opposite to those observed in the previous day model, and again the significance in the predictive power of the two variables suggest that cabdrivers' work hours are influenced by the beginning of the month wage and income. High wage in the beginning of the month will reduce the elasticity of the labor supply of cabdriver in the end of the month. However, if cabdrivers earn positive income in the beginning of the month, they are less likely to work shorter hours at the end of the months. The results in both the previous day and the beginning-of-the-month wage effects do explain some variations in the cabdriver labor supply.

\subsection{Reference-Dependence Preferences in Labor Supply}


Camerer et. al. (1997) attribute the negative labor supply elasticity in their results to target earnings behaviors of cabdrivers. Consistent with the reference-dependence preferences, target earnings imply a discontinuity in marginal utility of income at a reference level. A sharp kink is expected in the utility function, where cabdrivers always stop works when the reference/target income is earned for the day. Farber (2008), however, found evidence that constancy in the reference income across days of the week is strongly rejected, and that New York cabdrivers stop work way before the reference income level is reached. He claims that the results were inconsistent with reference dependence hypothesis, where stable targets influence negative cabdrivers’ decisions to stop works.

Crawford and Meng (2011) repeated the tests using the same data set as Farber (2008). Unlike the latent targets used in Farber (2008), they treat cabdrivers' income and hour targets as rational expectations using exogenous proxies from driver/day-of-the-week by driver/day-ofthe week point estimates of income and hours, excluding the day in questions. They estimate the probability of stopping work models using split samples of cabdrivers by their "early earnings' criteria, and their results show significant effects of the second target in predicting stopping of the cabdrivers' works. The results support the reference dependence hypothesis, which show that if the early earning targets have been reached, the stopping probabilities are significantly and positively correlated with the second (hours) target. The reversal is true, such that when the first (early) earning target is not met, the hours target is unlikely to explain the stopping probability of cabdrivers. ${ }^{11}$

Like Farber (2008) and Crawford and Meng (2010), we expand our tests on whether the reference dependence hypothesis holds in predicting the Singapore's cabdriver labor supply elasticity. Based on our unique dataset, we modify the estimation strategies for targets income and hours of Crawford and Meng (2010). We first use the driver-specific averages of day-byday income ("RATIO”) and hours ("POB”) for the sample periods (“calibration” periods) up to but excluding the "treatment" periods to proxy the targets. We also estimate the average driver-specific day-of-the-week by day-of-the week targets for income and hours based on the first three week calibration periods (August 1 to 21, 2010) as an alternative approach to control for day-of-the-week variations. We define two dummy variables indicating the above targets (i.e. cumulative income $>$ the target, and cumulative hours $>$ the target) by day and by

11 In our earlier results in Table 5 (last two columns), we observe variations in wage rate (surcharges) on labor supply elasticity, but the results are not conclusive in explaining whether stopping occurs when income and hours targets are reached. 
day-of the-week as the measures for incremental effects of hitting the target on the stopping probability models. We test the effects of the above target on the stopping probability using shifts/trips data in the last week of August 22 to 28, 2010, which is defined as the treatment (test) periods

In our Logit models, we define the stopping time probability using a dummy variable that has a value of 1 , if a driver stops work after a "POB” trip is made, and 0 otherwise. As the number POB trips increase, the probability of stopping also increases, which is consistent with Crawford and Meng (2010) model, though the first $x$ hour of the day is used by them in their model as the threshold. Our Logit regression results in Table 7, where the averages of all the days in the calibration periods are used in setting the targets, are consistent with the Crawford and Meng (2010) supporting the reference dependence theory in predicting the cabdrivers' probability of stopping works. The positive and significant coefficients on the cumulative efforts (both income and hours) above the targets imply that when the targets on income and hours are reached, the probability of cabdrivers stopping works increases. The results are consistent and significant across the model, when we control for weather, day of the week, and hour of the day effects (Columns 3 and 4). To adjust fare variations during the peak hours (6.00AM to $9.30 \mathrm{AM}$ and $6.00 \mathrm{PM}$ to $11.59 \mathrm{PM}$ ) and the midnight hours (12.00 midnight to 5.59AM), we assign weightages of $125 \%$ and $150 \%$ to the cumulative "POB" of the driver/day and driver/day-of-the week in Models (2) and (4), respectively. The weighting effects do not change the results; and the coefficients on the two above targets representing increment effects are still significant and positive. The coefficients on the cumulative hours on the "treated" working day are significant and positive, which are consistent with the negative labor supply elasticity results earlier. The results imply that cabdrivers whose cumulative works are high are more likely to stop works earlier. The cumulative income ("POB") coefficients are significant, but the signs change from negative to positive when variations in day of the week, hour of the day, and raining days are controlled. The positive effects of income are consistent with the neo-classical story of labor supply, but the magnitudes of the coefficients are small, but the economic significance is weak.

[Insert Table 7 here]

We repeat the Logit regressions that adjust for day-of-the-week variations in the targets for specific drivers, where the target for Monday is set based on the averages of the past three Mondays' averages from the calibration periods (August 1 to 21, 2010), and the same for 
other days of the week. Our results in Table 8 are consistent with those recorded in the earlier Table 7, where reference dependence is still significant in cabdrivers, when the targets of specific day of the week are used as the reference in the models. We expect the strong probability of stopping after hitting the target effort levels to be observed in cabdriver/day-ofthe-week by cabdriver/day-of-the-week. The constancy in the cabdrivers' stopping behavior is observed in Singapore also allay the criticism of Farber (2008) that the reference income is too unstable in predicting cabdrivers’ stopping behavior.

[Insert Table 8 here]

\section{Conclusion}

The debate of the wage elasticity in cabdriver labor supply between Camerer et. al. (1997) and Farber (2005) has not been resolved due to differences in econometric methodology, conceptual model and measurement of wage rates in the two methods. The referencedependent utility preference model (Farber, 2008, and Crawford and Meng, 2011) is used to describe the cabdrivers' target earning behavior in stopping work decisions. Again, no consensus has been reached between the two schools of thought on labor supply, where the neoclassical school represented by Farber (2008) found no significant effects of target income on stopping work probability of cabdrivers because most cabdrivers end shifts before reaching the target earnings. Crawford and Meng (2011) find evidence of asymmetric target income effects on cabdriver labor supply in supporting the behavioral story of Camerer et. al. (1997). They show that cabdrivers who fall short in target income in initial work hours are more likely to work longer (i.e. positive income effects on probability to stop work).

The earlier studies use two sets of different hand-collected trip sheet data from a small number of New York City cabdrivers, and measurement errors are recognized in the earlier studies. We collected high-frequency real time data through GPS-enabled technology installed in cabs of two largest operators in Singapore for the month of August 2010, and use the data to revisit on the wage elasticity debate for the cabdriver labor supply. After controlling for various heterogeneity and also cabdriver fixed effects in the model, we find evidence to support the negative wage elasticity effects of Camerer et. al. (1997), which predicts that cabdrivers do stop work earlier after their target earnings have been reached. However, our results show a much smaller elasticity of between -0.047 and -0.085 , compared to the elasticity estimates of -0.411 to -0.618 (unadjusted for fixed effects). The low negative wage elasticity in our results show some smoothness in cabdrivers' stopping probabilities in reacting to income target as 
shown in Farber (2008). Therefore, we reconcile that the neoclassical inter-temporal labor substitution effects are observed more clearly in "hardworking" cabdrivers, who work for longer hours per shift relative to "leisure” drivers with shorter work hours per shifts.

We also found significant variations in the negative labor supply elasticity among drivers working in the day shifts versus those working the night shifts, experience drivers versus new drivers, and also significant variations in cabdrivers' work hours during the peak periods versus the normal periods. There are also significant correlations in the previous day and the beginning-of-the month effort levels in explaining the variations in the work hours/shift of the drivers. The results all violate the assumptions of the neo-classical labor supply model, which are independent of the wage and income variations within a day or across day.

Like Farber (2008) and Crawford and Meng (2010), we also attempt to falsify the hypothesis as claimed by Camerer et. al. (1997) that the negative labor supply elasticity is attributed to the target income and work hours behaviors of cabdrivers. We follow Crawford and Meng's (2010) approach in estimating the targets by using the average income and hours by driver/day and also by driver/day-of-the-week. Our results show that hitting the targets early will have positive and significant impact on the probability of stopping works by cabdrivers. Cabdrivers who work up to the target cumulative hours and/or who earn the target income in a day are more likely to stop work earlier. The results do not reject the reference dependence hypothesis in the cabdriver labor supply.

We propose to further evaluate the transitory and permanent changes in income effects in the future studies by examine the effects of area-based fare variations on cabdrivers' stopping work probabilities. The proposed extension will require extensive spatial data on not just trip time, but trip route of cabdrivers. Experiment could be designed with our high-frequency data. One caveat in our study is that we assume no variations in area-based surcharge in our current estimates of wage elasticity. 


\section{References}

Altonji, Joseph G., 1986, Intertemporal Substitution in Labor Supply: Evidence from Micro Data, Journal of Political Economy, 94: 176-215.

Browning, Martin, Angus Deaton and Margaret Irish, 1985, A Profitable Approach to Labor Supply and Commodity Demands Over the Life Cycle, Econometrica, 53: 503-543.

Camerer, Colin, Linda Babcock, George Loewenstein, and Richard Thaler, 1997, Labor Supply of New York City Cabdrivers: One Day at a Time, Quarterly Journal of Economics, 112(2): 408-441

Crawford, Vincent P. and Juanjuan Meng, 2011, New York City Cab Drivers’ Labor Supply Revisited: Reference-Dependent Preference with Rational Expectations Targets for Hours and Income, American Economic Review, 101: 1912-1932.

Fehr, Ernst and Lorenz Goette, 2007, Do Workers Work More if Wages are High? Evidence from a Randomized Field Experiment, American Economic Review, 97(1): 298-317

Heckman, James J., 1974, Life Cycle Consumption and Labor Supply: An Explanation of the Relationship between Income and Consumption Over the Life Cycle, American Economic Review, 64(1): 188- 194.

Farber, Henry, 2005, Is Tomorrow Another Day? The Labor Supply of New York City Cabdrivers, Journal of Political Economy, 113(1): 46-82

Farber, Henry, 2008, Reference-dependent preferences and labor supply: the case of New York City taxi drivers, American Economic Review, 98(3): 1069-1082

Goette, Lorenz, Ernst Fehr, and David Huffman, 2004, Loss aversion and labor supply, Journal of the European Economic Association, 2(2-3): 216-228

Lucas, Robert E. Jr and Leonard A. Rapping, 1969, Real Wages, Employment, and Inflation, Journal of Political Economy, 77.

Köszegi, Botond, and Matthew Rabin, 2006, A Model of Reference-Dependent Preferences, Quarterly Journal of Economics, 121(4): 1133-1165

Mankiw, N. Gregory, Julio J. Rotemberg and Lawrence H. Summers, 1986, Intertemporal Substitution in Macroeconomics, Quarterly Journal of Economics, 100: 225-251.

Tversky, A., and Daniel Kahneman, 1991, Loss Aversion in Riskless Choice: A ReferenceDependent Model, Quarterly Journal of Economics, 106:1039-1061. 
Table 1: Summary Statistics by Days

\begin{tabular}{|c|c|c|c|c|c|c|c|c|c|c|c|c|c|c|c|}
\hline \multirow[b]{2}{*}{ Date } & \multirow[b]{2}{*}{ Day } & \multirow[b]{2}{*}{ Taxies } & \multirow[b]{2}{*}{ Drivers } & \multirow[b]{2}{*}{ Points } & \multicolumn{11}{|c|}{ Taxi Status } \\
\hline & & & & & Free & POB & Oncall & Arrived & Noshow & Payment & Break & Busy & STC & Offline & Poweroff \\
\hline Aug. 01 & Sunday & 15,305 & 23,437 & $13,835,333$ & 218 & 357 & 21 & 2 & 0 & 10 & 305 & 70 & 3 & 408 & 0 \\
\hline Aug. 02 & Monday & 15,390 & 25,592 & $17,096,870$ & 306 & 391 & 23 & 3 & 0 & 9 & 288 & 70 & 4 & 340 & 5 \\
\hline Aug. 03 & Tuesday & 15,393 & 25,266 & $17,738,104$ & 331 & 403 & 23 & 3 & 0 & 9 & 278 & 70 & 4 & 317 & 2 \\
\hline Aug. 04 & Wednesday & 15,416 & 25,531 & $17,731,631$ & 324 & 416 & 26 & 3 & 0 & 10 & 276 & 71 & 4 & 307 & 3 \\
\hline Aug. 05 & Thursday & 15,413 & 25,577 & $17,725,409$ & 318 & 426 & 26 & 3 & 0 & 10 & 277 & 72 & 4 & 303 & 2 \\
\hline Aug. 06 & Friday & 15,416 & 25,746 & $17,310,151$ & 280 & 462 & 31 & 3 & 0 & 10 & 280 & 71 & 4 & 297 & 2 \\
\hline Aug. 07 & Saturday & 15,384 & 25,504 & $16,431,043$ & 303 & 414 & 20 & 3 & 0 & 9 & 287 & 69 & 3 & 331 & 1 \\
\hline Aug. 08 & Sunday & 15,313 & 23,337 & $13,918,396$ & 252 & 363 & 18 & 2 & 0 & 10 & 320 & 70 & 3 & 401 & 1 \\
\hline Aug. 09 & Monday & 15,197 & 23,894 & $14,009,361$ & 282 & 299 & 14 & 2 & 0 & 8 & 315 & 73 & 3 & 442 & 2 \\
\hline Aug. 10 & Tuesday & 15,369 & 24,911 & $16,913,423$ & 299 & 398 & 24 & 3 & 0 & 10 & 287 & 71 & 4 & 337 & 7 \\
\hline Aug. 11 & Wednesday & 15,406 & 25,317 & $17,646,680$ & 318 & 406 & 25 & 3 & 0 & 9 & 278 & 72 & 4 & 319 & 5 \\
\hline Aug. 12 & Thursday & 15,420 & 25,514 & $17,827,659$ & 329 & 416 & 25 & 3 & 0 & 9 & 271 & 73 & 4 & 307 & 2 \\
\hline Aug. 13 & Friday & 15,427 & 25,767 & $17,197,322$ & 298 & 449 & 30 & 3 & 0 & 10 & 274 & 73 & 4 & 297 & 2 \\
\hline Aug. 14 & Saturday & 15,686 & 25,733 & $16,645,242$ & 323 & 402 & 20 & 2 & 0 & 9 & 276 & 69 & 3 & 327 & 7 \\
\hline Aug. 15 & Sunday & 15,315 & 23,680 & $15,031,228$ & 276 & 341 & 18 & 2 & 0 & 10 & 317 & 71 & 3 & 401 & 1 \\
\hline Aug. 16 & Monday & 15,382 & 25,664 & $17,515,041$ & 316 & 390 & 25 & 3 & 0 & 9 & 281 & 72 & 4 & 334 & 4 \\
\hline Aug. 17 & Tuesday & 15,381 & 25,215 & $17,772,021$ & 332 & 401 & 26 & 3 & 0 & 9 & 274 & 72 & 4 & 317 & 2 \\
\hline Aug. 18 & Wednesday & 15,381 & 25,418 & $18,040,192$ & 342 & 398 & 26 & 3 & 0 & 9 & 272 & 73 & 4 & 310 & 2 \\
\hline Ang. 19 & Thursday & 15,401 & 25,490 & $18,302,104$ & 349 & 401 & 25 & 3 & 0 & 10 & 266 & 72 & 4 & 307 & 3 \\
\hline Aug. 20 & Friday & 15,423 & 25,727 & $17,277,778$ & 283 & 454 & 34 & 4 & 0 & 10 & 275 & 73 & 4 & 302 & 3 \\
\hline Aug. 21 & Saturday & 15,396 & 25,568 & $16,356,668$ & 304 & 419 & 21 & 3 & 0 & 10 & 285 & 71 & 3 & 324 & 1 \\
\hline Aug. 22 & Sunday & 15,308 & 23,553 & $14,439,076$ & 260 & 341 & 18 & 2 & 0 & 10 & 323 & 73 & 3 & 409 & 1 \\
\hline Aug. 23 & Monday & 15,359 & 25,481 & $17,219,693$ & 307 & 389 & 27 & 3 & 0 & 9 & 284 & 73 & 4 & 340 & 5 \\
\hline Aug. 24 & Tuesday & 15,445 & 25,117 & $17,671,728$ & 325 & 390 & 24 & 3 & 0 & 9 & 286 & 72 & 4 & 324 & 4 \\
\hline Aug. 25 & Wednesday & 15,422 & 25,438 & $18,146,962$ & 341 & 398 & 24 & 3 & 0 & 10 & 272 & 71 & 4 & 312 & 6 \\
\hline Aug. 26 & Thursday & 15,468 & 25,562 & $18,065,342$ & 327 & 418 & 26 & 3 & 0 & 10 & 271 & 72 & 4 & 306 & 3 \\
\hline Aug. 27 & Friday & 15,569 & 25,763 & $17,322,698$ & 286 & 451 & 32 & 3 & 0 & 10 & 277 & 74 & 4 & 299 & 3 \\
\hline Aug. 28 & Saturday & 15,455 & 25,734 & $16,106,636$ & 296 & 426 & 21 & 2 & 0 & 10 & 283 & 69 & 3 & 327 & 1 \\
\hline Aug. 29 & Sunday & 15,411 & 23,657 & $14,402,482$ & 258 & 347 & 19 & 2 & 0 & 10 & 321 & 72 & 3 & 405 & 3 \\
\hline Aug. 30 & Monday & 15,469 & 25,758 & $17,279,287$ & 311 & 390 & 24 & 3 & 0 & 9 & 283 & 70 & 4 & 339 & 7 \\
\hline Aug. 31 & Tuesday & 15,457 & 25,466 & $17,622,960$ & 316 & 415 & 25 & 3 & 0 & 10 & 280 & 70 & 4 & 315 & 2 \\
\hline
\end{tabular}




\begin{tabular}{|c|c|c|c|c|}
\hline & & & $\begin{array}{r}\text { Monthly } \\
\text { Total (min) }\end{array}$ & $\begin{array}{r}\text { Daily } \\
\text { Average } \\
\text { (min) }\end{array}$ \\
\hline 1 & Vehicle is free to take a passenger & Free & $144,991,325$ & 304 \\
\hline 2 & Passenger is on board & POB & $190,637,213$ & 399 \\
\hline 3 & Vehicle is "on call”. Not available for street hire. & Oncall & $11,396,500$ & 24 \\
\hline 4 & $\begin{array}{l}\text { Vehicle has reached the pickup location of a booking } \\
\text { job and driver has pressed arrived button. }\end{array}$ & Arrived & $1,389,675$ & 3 \\
\hline 5 & $\begin{array}{l}\text { Driver has pressed "no show" button since the } \\
\text { passenger who has booked job did not turn up at the } \\
\text { pickup location. }\end{array}$ & Noshow & 478 & 0 \\
\hline 6 & Cashless payment is in progress & Payment & $4,545,621$ & 10 \\
\hline 7 & Vehicle is not to free to take a passenger & Break & $136,537,356$ & 286 \\
\hline 8 & Vehicle is not to free to take a passenger & Busy & $34,090,694$ & 71 \\
\hline 9 & $\begin{array}{l}\text { Soon to Clear. Vehicle will become free in short } \\
\text { time. }\end{array}$ & STC & $1,740,376$ & 4 \\
\hline 10 & Driver has logged off from the MDT. & Offline & $160,228,126$ & 336 \\
\hline 11 & The radio signal is switched off & Poweroff & $1,450,434$ & 3 \\
\hline
\end{tabular}

Note: Working status = [POB, FREE, PAYMENT, ONCALL, ARRIVED, and NOSHOW]. Nonworking status $=[$ BUSY, BREAK, STC, OFFLINE, and POWEROFF $]$. 
Table 3: OLS models of worked hours on wage rate for cabdrivers

\begin{tabular}{|c|c|c|c|c|c|c|c|c|}
\hline \multirow[b]{2}{*}{ Intercept } & \multicolumn{2}{|c|}{ OLS Model 1} & \multicolumn{2}{|c|}{ OLS Model 2} & \multicolumn{2}{|c|}{ OLS Model 3} & \multicolumn{2}{|c|}{ OLS Model 4} \\
\hline & 660.762 & $* * *$ & 6.279 & $* * *$ & 744.381 & $* * *$ & 6.419 & $* * *$ \\
\hline & [0.805] & & [0.001] & & [0.845] & & {$[0.001]$} & \\
\hline \multirow[t]{2}{*}{ RATIO } & -169.620 & $* * *$ & & & -166.143 & $* * *$ & & \\
\hline & [1.703] & & & & [1.614] & & & \\
\hline \multirow[t]{2}{*}{ Log(RATIO) } & & & -0.059 & $* * *$ & & & -0.057 & $* * *$ \\
\hline & & & [0.001] & & & & {$[0.001]$} & \\
\hline \multirow[t]{2}{*}{ Sunday } & & & & & -49.748 & $* * *$ & -0.105 & $* * *$ \\
\hline & & & & & {$[0.620]$} & & [0.001] & \\
\hline \multirow[t]{2}{*}{ Saturday } & & & & & -9.369 & $* * *$ & -0.024 & $* * *$ \\
\hline & & & & & [0.661] & & [0.001] & \\
\hline \multirow[t]{2}{*}{ Nationalday } & & & & & -80.281 & $* * *$ & -0.154 & $* * *$ \\
\hline & & & & & [1.196] & & [0.002] & \\
\hline \multirow[t]{2}{*}{ Night } & & & & & -10.898 & $* * *$ & -0.017 & $* * *$ \\
\hline & & & & & [0.433] & & [0.001] & \\
\hline \multirow[t]{2}{*}{ Rain_high } & & & & & 3.724 & $* * *$ & 0.006 & $* * *$ \\
\hline & & & & & [0.497] & & [0.001] & \\
\hline \multirow[t]{2}{*}{ Rain_low } & & & & & 4.641 & $* * *$ & 0.007 & $* * *$ \\
\hline & & & & & [0.544] & & [0.001] & \\
\hline \multirow[t]{2}{*}{ Is2driver } & & & & & -102.815 & $* * *$ & -0.160 & $* * *$ \\
\hline & & & & & [0.448] & & [0.001] & \\
\hline \multirow[t]{2}{*}{ Driver_old } & & & & & -12.395 & $* * *$ & -0.018 & $* * *$ \\
\hline & & & & & [0.443] & & {$[0.001]$} & \\
\hline
\end{tabular}

The table summarizes the OLS regression results with the worked hours per shift of cabdrivers (T_SHIFT) as the dependent variable. We define wage rate using the RATIO and log(RATIO) as our independent variable controlling with other day-by-week (Saturday and Sunday) and public holiday (Nationlday) dummies, and cabdriver dummies (NIGHT = night-shift drivers; IS2driver = 2-shift drivers, Driver_old $=$ experienced cabdrivers), and also weather effects (Rain_high $=$ days with rail falls $>0.8$ inch and Rain_low = days with rain falls $<0.1$ inch). The numbers in the first row are the regression coefficients, and the numbers in brackets are the standard errors. "****" denotes significance at 1\% level, “**” denotes significance at $5 \%$ level, and “*” denotes significance at $10 \%$ level. 
Table 4: Fixed Cabdriver Effect Models of Cabdriver Labor Supply

\begin{tabular}{|c|c|c|c|c|c|c|c|c|c|c|}
\hline \multirow{3}{*}{$\begin{array}{l}\text { Sample } \\
\text { Dependent Var. } \\
\text { Intercept }\end{array}$} & All & & \multicolumn{2}{|l|}{ All } & \multicolumn{2}{|l|}{ All } & \multicolumn{2}{|c|}{$\begin{array}{l}\text { Leisure drivers } \\
\text { ( } 1^{\text {st }} \text { Quartile by } \\
\text { POB })\end{array}$} & \multicolumn{2}{|c|}{$\begin{array}{c}\text { Hardworking } \\
\text { Drivers (4 } \\
\text { Quartile by } \\
\text { POB) }\end{array}$} \\
\hline & t_shift & & \multicolumn{2}{|c|}{$\log$ t_shift } & \multicolumn{2}{|l|}{ log t_shift } & \multicolumn{2}{|c|}{ log t_shift } & \multicolumn{2}{|l|}{$\log t$ t_shift } \\
\hline & 738.585 & $* * *$ & 6.424 & $* * *$ & 6.447 & $* * *$ & 6.097 & $* * *$ & 6.406 & $* * *$ \\
\hline & [0.905] & & [0.001] & & [0.001] & & [0.004] & & [0.004] & \\
\hline \multirow[t]{2}{*}{ ratio } & -156.005 & $* * *$ & & & & & & & & \\
\hline & [1.699] & & & & & & & & & \\
\hline \multirow[t]{2}{*}{ log_ratio } & & & -0.063 & $* * *$ & & & -0.085 & $* * *$ & -0.047 & $* * *$ \\
\hline & & & [0.001] & & & & [0.003] & & {$[0.003]$} & \\
\hline \multirow[t]{2}{*}{ log_ratio_wt } & & & & & -0.042 & $* * *$ & & & & \\
\hline & & & & & [0.001] & & & & & \\
\hline \multirow[t]{2}{*}{ sunday } & -56.079 & $* * *$ & -0.118 & $* * *$ & -0.121 & $* * *$ & -0.095 & $* * *$ & -0.128 & $* * *$ \\
\hline & [0.492] & & [0.001] & & [0.001] & & [0.003] & & {$[0.002]$} & \\
\hline \multirow[t]{2}{*}{ saturday } & -15.145 & $* * *$ & -0.034 & $* * *$ & -0.037 & $* * *$ & -0.044 & $* * *$ & -0.013 & $* * *$ \\
\hline & {$[0.504]$} & & [0.001] & & {$[0.001]$} & & [0.003] & & {$[0.002]$} & \\
\hline \multirow[t]{2}{*}{ nationalday } & -82.770 & $* * *$ & -0.162 & $* * *$ & -0.161 & $* * *$ & -0.162 & $* * *$ & -0.138 & $* * *$ \\
\hline & [0.900] & & [0.002] & & [0.002] & & [0.004] & & {$[0.004]$} & \\
\hline \multirow[t]{2}{*}{ night } & -96.228 & $* * *$ & -0.172 & $* * *$ & -0.170 & $* * *$ & -0.151 & $* * *$ & -0.523 & $* * *$ \\
\hline & [0.924] & & [0.002] & & [0.002] & & [0.005] & & {$[0.005]$} & \\
\hline \multirow[t]{2}{*}{ rain_high } & 2.734 & $* * *$ & 0.004 & $* * *$ & 0.004 & $* * *$ & 0.004 & $* *$ & 0.003 & $* *$ \\
\hline & [0.371] & & [0.001] & & [0.001] & & [0.002] & & {$[0.001]$} & \\
\hline \multirow[t]{2}{*}{ rain_low } & 3.859 & $* * *$ & 0.006 & $* * *$ & 0.006 & $* * *$ & 0.006 & $* * *$ & 0.004 & $* *$ \\
\hline & {$[0.406]$} & & {$[0.001]$} & & {$[0.001]$} & & [0.002] & & {$[0.002]$} & \\
\hline \multirow[t]{2}{*}{ is2driver } & -56.793 & $* * *$ & -0.092 & $* * *$ & -0.092 & $* * *$ & -0.090 & $* * *$ & -0.102 & $* * *$ \\
\hline & {$[0.466]$} & & [0.001] & & [0.001] & & [0.002] & & {$[0.002]$} & \\
\hline \multirow[t]{2}{*}{ pct_peak } & & & & & & & 0.030 & $* * *$ & 0.516 & $* * *$ \\
\hline & & & & & & & {$[0.006]$} & & {$[0.007]$} & \\
\hline \multirow[t]{2}{*}{ pct_night } & & & & & & & 0.643 & $* * *$ & 1.022 & $* * *$ \\
\hline & & & & & & & [0.012] & & {$[0.014]$} & \\
\hline Fixed Effects & Yes & & Yes & & Yes & & Yes & & Yes & \\
\hline Adj R-squared & 0.523 & & 0.472 & & 0.470 & & 0.293 & & 0.325 & \\
\hline Root MSE & 106.762 & & 0.216 & & 0.216 & & 0.213 & & 0.183 & \\
\hline F Stat. & 6809.380 & & 5118.960 & & 4904.210 & & 963.570 & & 3434.400 & \\
\hline
\end{tabular}

The table summarizes the results of Fixed Effect regression models with the worked hours per shift of cabdrivers (T_SHIFT) and its log version as the dependent variables. We define wage rate using the RATIO and log(RATIO) as our independent variable controlling with other day-by-week (Saturday and Sunday) and public holiday (Nationlday) dummies, and cabdriver dummies (NIGHT = night-shift drivers; IS2driver = 2-shift drivers, Driver_old = experienced cabdrivers), weather effects (Rain_high = days with rail falls $>0.8$ inch and Rain_low = days with rain falls $<0.1$ inch) and (pct_peak $=$ ? and pct_night $=$ ?). The numbers in the first row are the regression coefficients, and the numbers in brackets are the standard errors. “***” denotes significance at $1 \%$ level, “**” denotes significance at $5 \%$ level, and “*” denotes significance at $10 \%$ level. 
Table 5: Heterogeneity of Cabdrivers and Fare Variations

\begin{tabular}{|c|c|c|c|c|c|c|c|c|c|c|c|c|}
\hline \multirow{3}{*}{$\begin{array}{l}\text { Sorting } \\
\text { Intercept }\end{array}$} & \multicolumn{8}{|c|}{ Drivers' Heterogeneity } & \multicolumn{4}{|c|}{ Fare Variation } \\
\hline & \multicolumn{2}{|c|}{ Experience } & \multicolumn{2}{|l|}{ New } & \multicolumn{2}{|c|}{ 1-shift } & \multicolumn{2}{|c|}{ 2-shift } & \multicolumn{2}{|c|}{$\begin{array}{l}\text { Fare with } \\
\text { surcharge }\end{array}$} & \multicolumn{2}{|c|}{ Regular fare } \\
\hline & 6.373 & $* * *$ & 6.466 & $* * *$ & 6.462 & $* * *$ & 6.256 & $* * *$ & 5.571 & $* * *$ & 6.185 & $* * *$ \\
\hline & {$[0.003]$} & & {$[0.003]$} & & {$[0.002]$} & & {$[0.002]$} & & {$[0.020]$} & & [0.011] & \\
\hline \multirow[t]{2}{*}{ log_ratio } & -0.090 & $* * *$ & -0.039 & $* * *$ & -0.074 & $* * *$ & -0.057 & $* * *$ & -0.054 & $* * *$ & -0.067 & $* * *$ \\
\hline & {$[0.002]$} & & {$[0.003]$} & & {$[0.002]$} & & {$[0.001]$} & & {$[0.008]$} & & {$[0.008]$} & \\
\hline \multirow[t]{2}{*}{ sunday } & -0.096 & $* * *$ & -0.155 & $* * *$ & -0.190 & $* * *$ & -0.087 & $* * *$ & -0.047 & $* * *$ & -0.101 & $* * *$ \\
\hline & {$[0.002]$} & & {$[0.002]$} & & [0.002] & & {$[0.001]$} & & {$[0.011]$} & & {$[0.010]$} & \\
\hline \multirow[t]{2}{*}{ saturday } & -0.027 & $* * *$ & -0.043 & $* * *$ & -0.081 & $* * *$ & -0.015 & $* * *$ & 0.072 & $* * *$ & -0.036 & $* * *$ \\
\hline & {$[0.002]$} & & {$[0.002]$} & & [0.002] & & {$[0.001]$} & & {$[0.010]$} & & [0.010] & \\
\hline \multirow[t]{2}{*}{ nationalday } & -0.137 & $* * *$ & -0.200 & $* * *$ & -0.237 & $* * *$ & -0.127 & $* * *$ & -0.065 & $* * *$ & -0.171 & $* * *$ \\
\hline & [0.003] & & [0.004] & & [0.004] & & [0.002] & & [0.015] & & [0.013] & \\
\hline \multirow[t]{2}{*}{ night } & -0.150 & $* * *$ & -0.189 & $* * *$ & -0.321 & $* * *$ & -0.024 & $* * *$ & 0.522 & $* * *$ & -0.659 & $* * *$ \\
\hline & [0.004] & & [0.004] & & [0.004] & & {$[0.002]$} & & [0.019] & & {$[0.066]$} & \\
\hline \multirow[t]{2}{*}{ rain_high } & 0.003 & $* *$ & 0.006 & $* * *$ & 0.010 & $* * *$ & 0.004 & $* * *$ & 0.008 & & 0.004 & \\
\hline & [0.001] & & [0.002] & & [0.002] & & {$[0.001]$} & & [0.006] & & [0.007] & \\
\hline \multirow[t]{2}{*}{ rain_low } & 0.006 & $* * *$ & 0.006 & $* * *$ & 0.012 & $* * *$ & 0.004 & $* * *$ & 0.002 & & 0.013 & \\
\hline & [0.002] & & [0.002] & & [0.002] & & {$[0.001]$} & & [0.006] & & [0.008] & \\
\hline \multirow[t]{2}{*}{ is2driver } & -0.093 & $* * *$ & -0.092 & $* * *$ & & & & & 0.001 & & -0.069 & $* * *$ \\
\hline & [0.002] & & [0.002] & & & & & & [0.010] & & [0.007] & \\
\hline Adj $R^{2}$ & 0.502 & & 0.427 & & 0.424 & & 0.511 & & 0.751 & & 0.517 & \\
\hline Root MSE & 0.203 & & 0.237 & & 0.246 & & 0.188 & & 0.195 & & 0.241 & \\
\hline F Stat. & 1320.580 & & 1252.720 & & 3489.750 & & 1607.240 & & 111.880 & & 56.770 & \\
\hline
\end{tabular}

The table summarizes the results of Fixed Effect regression models with the log-worked hours per shift of cabdrivers (Log-T_SHIFT) as the dependent variables. We define wage rate using the RATIO and $\log (\mathrm{RATIO})$ as our independent variable controlling with other day-by-week (Saturday and Sunday) and public holiday (Nationlday) dummies, and cabdriver dummies $($ NIGHT $=$ night-shift drivers; IS2driver $=2$-shift drivers, Driver_old $=$ experienced cabdrivers), and also weather effects (Rain_high = days with rail falls $>0.8$ inch and Rain_low = days with rain falls $<0.1$ inch). The numbers in the first row are the regression coefficients, and the numbers in brackets are the standard errors. "***" denotes significance at 1\% level, "**” denotes significance at 5\% level, and “*” denotes significance at 10\% level. 
Table 6: Serial Correlations in Total Work Hours per Shift

\begin{tabular}{|c|c|c|c|c|}
\hline Sample & All & & Obs. in Week 4 & \\
\hline Lagged period: & Previous day & & First Week & \\
\hline \multirow[t]{2}{*}{ log_t_pob_lag } & -0.002 & $* * *$ & 0.722 & *** \\
\hline & {$[0.001]$} & & {$[0.003]$} & \\
\hline \multirow[t]{2}{*}{ log_ratio_lag } & 0.005 & $* * *$ & -0.661 & $* * *$ \\
\hline & [0.001] & & [0.005] & \\
\hline \multirow[t]{2}{*}{ log_ratio } & -0.062 & $* * *$ & -0.077 & $* * *$ \\
\hline & {$[0.001]$} & & {$[0.002]$} & \\
\hline \multirow[t]{2}{*}{ Sunday } & -0.110 & $* * *$ & -0.106 & $* * *$ \\
\hline & {$[0.001]$} & & {$[0.002]$} & \\
\hline \multirow[t]{2}{*}{ Saturday } & -0.035 & $* * *$ & -0.005 & $* *$ \\
\hline & [0.001] & & {$[0.003]$} & \\
\hline \multirow[t]{2}{*}{ Nationalday } & -0.161 & $* * *$ & & \\
\hline & {$[0.002]$} & & & \\
\hline \multirow[t]{2}{*}{ Night } & -0.166 & $* * *$ & -0.015 & $* * *$ \\
\hline & {$[0.002]$} & & {$[0.001]$} & \\
\hline \multirow[t]{2}{*}{ Rain_high } & 0.009 & $* * *$ & -0.004 & $* *$ \\
\hline & {$[0.001]$} & & {$[0.002]$} & \\
\hline \multirow[t]{2}{*}{ Rain_low } & 0.007 & $* * *$ & -0.024 & $* * *$ \\
\hline & {$[0.001]$} & & {$[0.002]$} & \\
\hline \multirow[t]{2}{*}{ is2driver } & -0.091 & $* * *$ & -0.076 & $* * *$ \\
\hline & {$[0.001]$} & & [0.002] & \\
\hline \multirow[t]{2}{*}{ driver_old } & & & 0.000 & \\
\hline & & & {$[0.002]$} & \\
\hline \multirow[t]{2}{*}{ Intercept } & 6.437 & $* * *$ & 1.809 & $* * *$ \\
\hline & {$[0.006]$} & & {$[0.021]$} & \\
\hline Fixed Effects & Yes & & No & \\
\hline Adj R-squared & 0.479 & & 0.358 & \\
\hline Root MSE & 0.212 & & 0.233 & \\
\hline F Stat. & 3618.790 & & 6827.030 & \\
\hline
\end{tabular}

The table summarizes the results of the OLS regression models with the log-worked hours per shift of cabdrivers (Log-T_SHIFT) as the dependent variables Our independent variables include the wage rate defined as $\log (R A T I O)$, the lagged log(RATIO) and the lagged income variables, defined as log-POB. Two lag periods are used in our tests that include the prvious day lag and also the first week-of-the-month lag. We also control for other day-by-week (Saturday and Sunday) and public holiday (Nationlday) dummies, and cabdriver dummies $($ NIGHT $=$ night-shift drivers; IS2driver $=2$-shift drivers, Driver_old $=$ experienced cabdrivers), and also weather effects (Rain_high = days with rail falls $>0.8$ inch and Rain_low = days with rain falls $<0.1$ inch). The numbers in the first row are the regression coefficients, and the numbers in brackets are the standard errors. "***” denotes significance at $1 \%$ level, “**” denotes significance at $5 \%$ level, and “*” denotes significance at $10 \%$ level. 


\begin{tabular}{|c|c|c|c|c|c|c|c|c|}
\hline \multirow{4}{*}{$\begin{array}{l}\text { Cumulative total working } \\
\text { hours > working hour target }\end{array}$} & \multicolumn{8}{|c|}{$\begin{array}{l}\text { Using driver specific sample average income and } \\
\text { working time prior to the current shift as target }\end{array}$} \\
\hline & \multirow{2}{*}{$\begin{array}{c}(1) \\
0.601\end{array}$} & \multicolumn{3}{|c|}{$(2)$} & \multirow{2}{*}{$\begin{array}{c}(3) \\
0.259\end{array}$} & \multicolumn{3}{|c|}{ (4) } \\
\hline & & $* * *$ & 0.611 & $* * *$ & & $* * *$ & 0.257 & $* * *$ \\
\hline & [0.009] & & {$[0.009]$} & & [0.012] & & [0.012] & \\
\hline \multirow{2}{*}{$\begin{array}{l}\text { Cumulative total income } \\
\text { (POB hours) > income (POB } \\
\text { hours) target }\end{array}$} & 1.155 & $* * *$ & 1.096 & $* * *$ & 0.202 & $* * *$ & 0.211 & *** \\
\hline & [0.009] & & [0.009] & & [0.011] & & [0.011] & \\
\hline \multirow{2}{*}{$\begin{array}{l}\text { Cumulative total working } \\
\text { hours (min) }\end{array}$} & 0.006 & $* * *$ & 0.005 & $* * *$ & 0.011 & $* * *$ & 0.011 & *** \\
\hline & {$[0.000]$} & & {$[0.000]$} & & {$[0.000]$} & & {$[0.000]$} & \\
\hline \multirow{2}{*}{$\begin{array}{l}\text { Cumulative POB hours } \\
\text { (min) }\end{array}$} & -0.003 & $* * *$ & -0.001 & $* * *$ & 0.004 & $* * *$ & 0.003 & $* * *$ \\
\hline & {$[0.000]$} & & {$[0.000]$} & & {$[0.000]$} & & {$[0.000]$} & \\
\hline Weather & No & & No & & Yes & & Yes & \\
\hline Days of week & No & & No & & Yes & & Yes & \\
\hline Hour of the day & No & & No & & Yes & & Yes & \\
\hline Using weighted POB time & No & & Yes & & No & & Yes & \\
\hline \multirow[t]{2}{*}{ Log likelihood } & - & & - & & - & & - & \\
\hline & 361222 & & 361398 & & 251244 & & 251245 & \\
\hline Pseudo $\mathrm{R}^{2}$ & 0.233 & & 0.233 & & n.a. & & n.a. & \\
\hline \multirow[t]{2}{*}{ Observations } & 228948 & & 228948 & & 228947 & & 228947 & \\
\hline & 8 & & 8 & & 0 & & 0 & \\
\hline
\end{tabular}

The table summarizes the results of the Logit regression models with the probability of stopping works after each $\triangle O B$ trip as the dependent variables. Our independent variables include the cumulative work hours after a $\mathrm{POB}$ trip and cumulative income after a $\mathrm{POB}$ trip, and two dummy variables indicating that the cumulative work hours exceeding the target work hour, and the cumulative income (POB hours) exceeding the target income. In Columns (1) and (3), the "POB" is weighted for the wage variations during the peak hours and midnight hours. We weight the POB by $125 \%$ for the peak hours (6.00AM to 9.30AM and 6.00PM to 11.59PM), and 150\% for the midnight hours (12.00 midnight to 5.569AM). In Columns (3) and (4), we control for other day-of-the-week (Monday to Saturday with Sunday as the reference day), and weather (Rain_low as the reference in the dummy), and hours-ofthe-day (with the first hour of the day 0000 hours to 0059 hours as the reference hour), and IS2driver $=2$-shift drivers. The numbers in the first row are the regression coefficients, and the numbers in brackets are the standard errors. “***” denotes significance at 1\% level, “**” denotes significance at $5 \%$ level, and “*” denotes significance at $10 \%$ level. 


\begin{tabular}{|c|c|c|c|c|c|c|c|c|}
\hline \multirow{4}{*}{$\begin{array}{l}\text { Cumulative total working } \\
\text { hours }>\text { working hour target }\end{array}$} & \multicolumn{8}{|c|}{$\begin{array}{l}\text { Using driver and day-of-week specific sample average } \\
\text { income and working time prior to the current shift as } \\
\text { target }\end{array}$} \\
\hline & (1) & \multicolumn{2}{|r|}{ (2) } & \multicolumn{2}{|r|}{ (3) } & \multicolumn{3}{|c|}{ (4) } \\
\hline & 0.715 & $* * *$ & 0.723 & $* * *$ & 0.640 & $* * *$ & 0.625 & $* * *$ \\
\hline & [0.009] & & [0.009] & & [0.011] & & {$[0.011]$} & \\
\hline \multirow{2}{*}{$\begin{array}{l}\text { Cumulative total income } \\
\text { (POB hours) > income (POB } \\
\text { hours) target }\end{array}$} & 1.197 & $* * *$ & 1.168 & $* * *$ & 0.628 & $* * *$ & 0.656 & $* * *$ \\
\hline & {$[0.008]$} & & [0.008] & & [0.010] & & [0.010] & \\
\hline \multirow{2}{*}{$\begin{array}{l}\text { Cumulative total working } \\
\text { hours (min) }\end{array}$} & 0.006 & $* * *$ & 0.005 & $* * *$ & 0.010 & $* * *$ & 0.010 & *** \\
\hline & {$[0.000]$} & & {$[0.000]$} & & {$[0.000]$} & & {$[0.000]$} & \\
\hline \multirow{2}{*}{$\begin{array}{l}\text { Cumulative POB hours } \\
\text { (min) }\end{array}$} & -0.002 & $* * *$ & 0.000 & & 0.002 & $* * *$ & 0.002 & *** \\
\hline & [0.000] & & [0.000] & & {$[0.000]$} & & {$[0.000]$} & \\
\hline Weather & No & & No & & Yes & & Yes & \\
\hline Days of week & No & & No & & Yes & & Yes & \\
\hline Hour of the day & No & & No & & Yes & & Yes & \\
\hline Using weighted POB time & No & & Yes & & No & & Yes & \\
\hline \multirow[t]{2}{*}{ Log likelihood } & - & & - & & - & & - & \\
\hline & 354957 & & 354599 & & 246277 & & 246065 & \\
\hline Pseudo $\mathrm{R}^{2}$ & 0.247 & & 0.247 & & n.a. & & n.a. & \\
\hline \multirow[t]{2}{*}{ Observations } & 228948 & & 228948 & & 228947 & & 228947 & \\
\hline & 8 & & 8 & & 0 & & 0 & \\
\hline
\end{tabular}

The table summarizes the results of the Logit regression models with the probability of stopping works after each $\mathrm{POB}$ trip as the dependent variables. Our independent variables include the cumulative work hours after a $\mathrm{POB}$ trip and cumulative income after a POB trip, and two dummy variables indicating that the cumulative work hours exceeding the target work hour, and the cumulative income (POB hours) exceeding the target income. In Columns (1) and (3), the "POB" is weighted for the wage variations during the peak hours and midnight hours. We weight the POB by $125 \%$ for the peak hours (6.00AM to 9.30AM and 6.00PM to 11.59PM), and 150\% for the midnight hours (12.00 midnight to 5.569AM). In Columns (3) and (4), we control for other day-of-the-week (Monday to Saturday with Sunday as the reference day), and weather (Rain_low as the reference in the dummy), and hours-ofthe-day (with the first hour of the day 0000 hours to 0059 hours as the reference hour), and IS2driver $=2$-shift drivers. The numbers in the first row are the regression coefficients, and the numbers in brackets are the standard errors. "***” denotes significance at 1\% level, “**” denotes significance at $5 \%$ level, and “*” denotes significance at 10\% level. 
Figure 1 Distributions of Cabs per minutes by Status for the full Sample (August 2010)

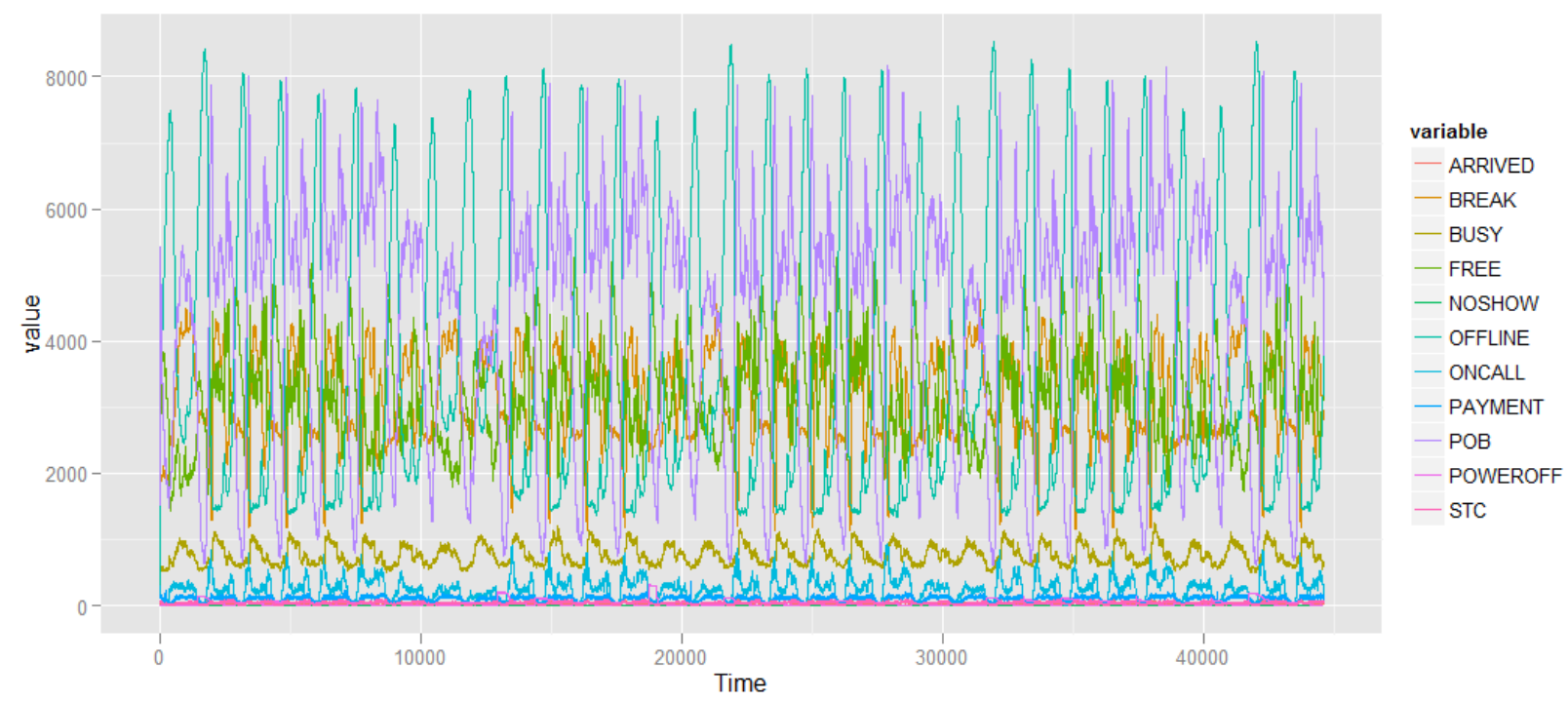

Figure 2 Distributions of Cabs per minutes by Status for the week of August 15-21, 2010

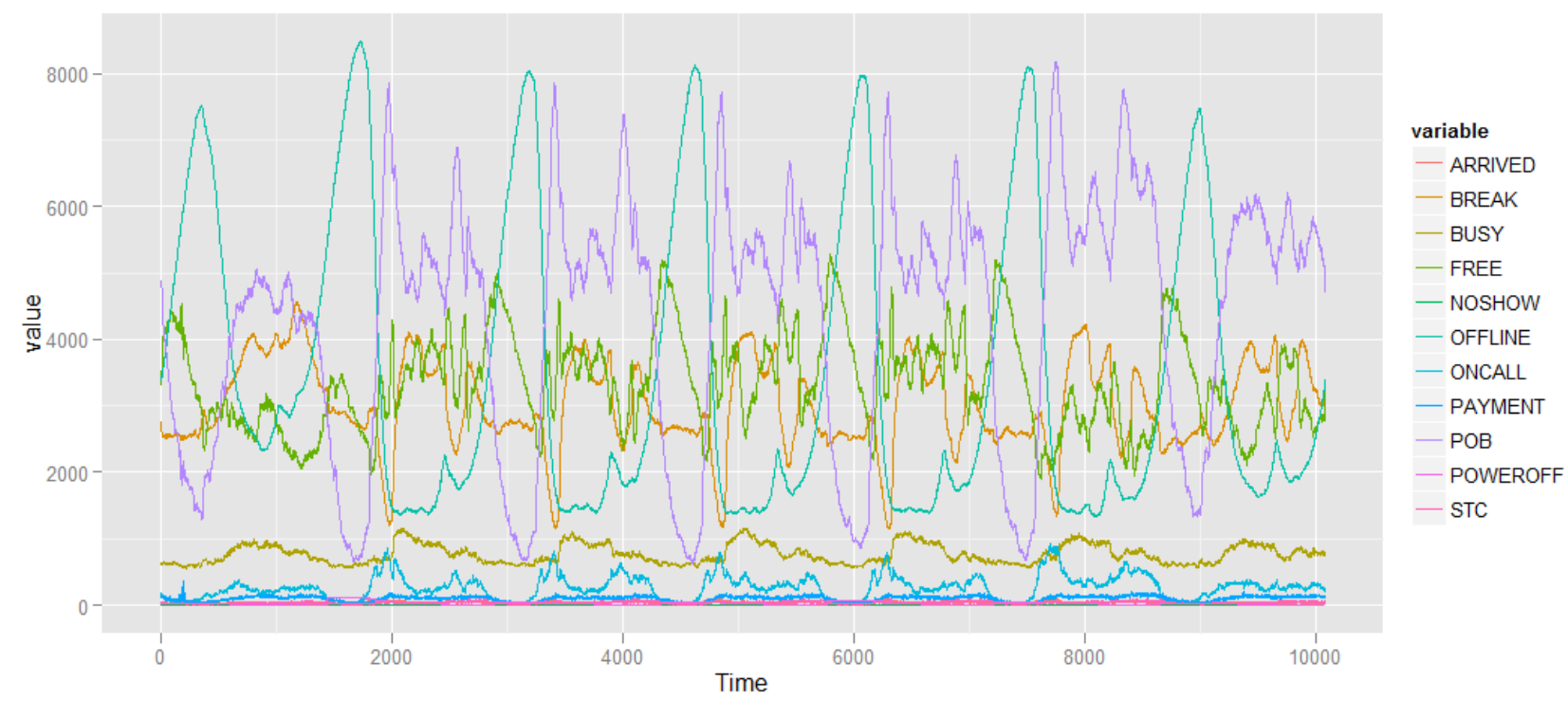


Figure 3 Inter-day Comparison of Cab Activities
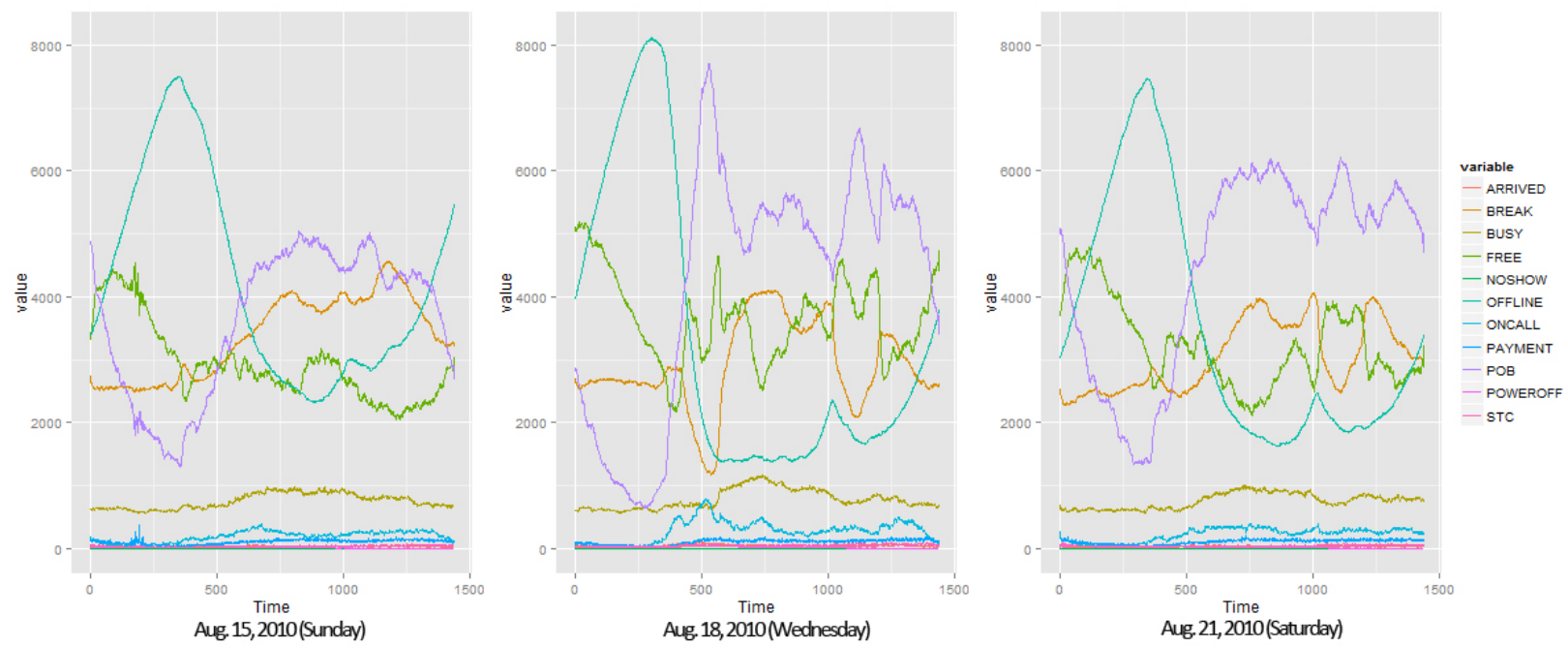
Figure 4 Intra-day Variations in Cab Activities

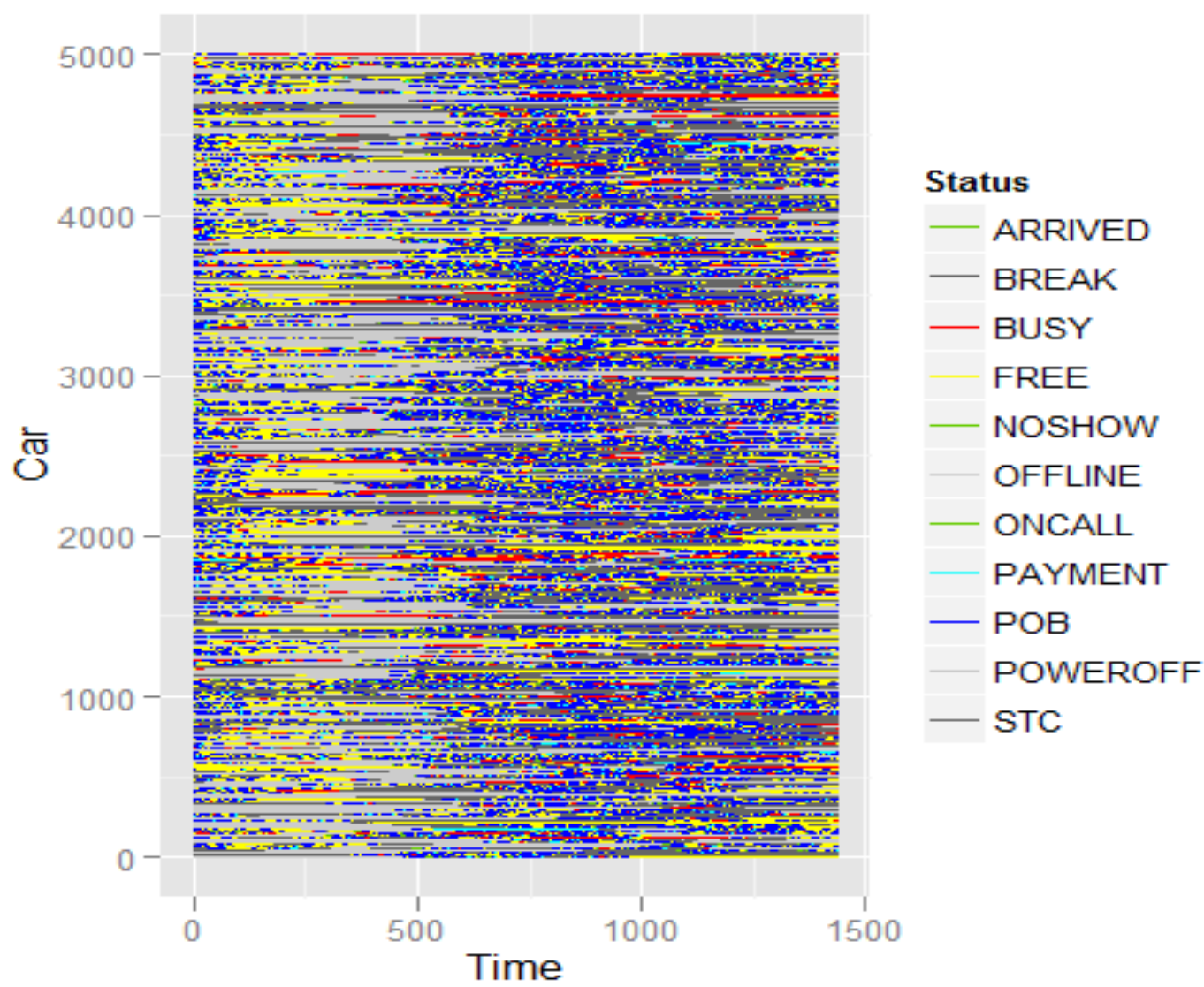

Note: Each line in this chart represents a taxi (5000 in total) 
Figure 5: Distributions of Day-by-Day Supply and Demand of Cab Services and Wage Rate for the Month of August 2010

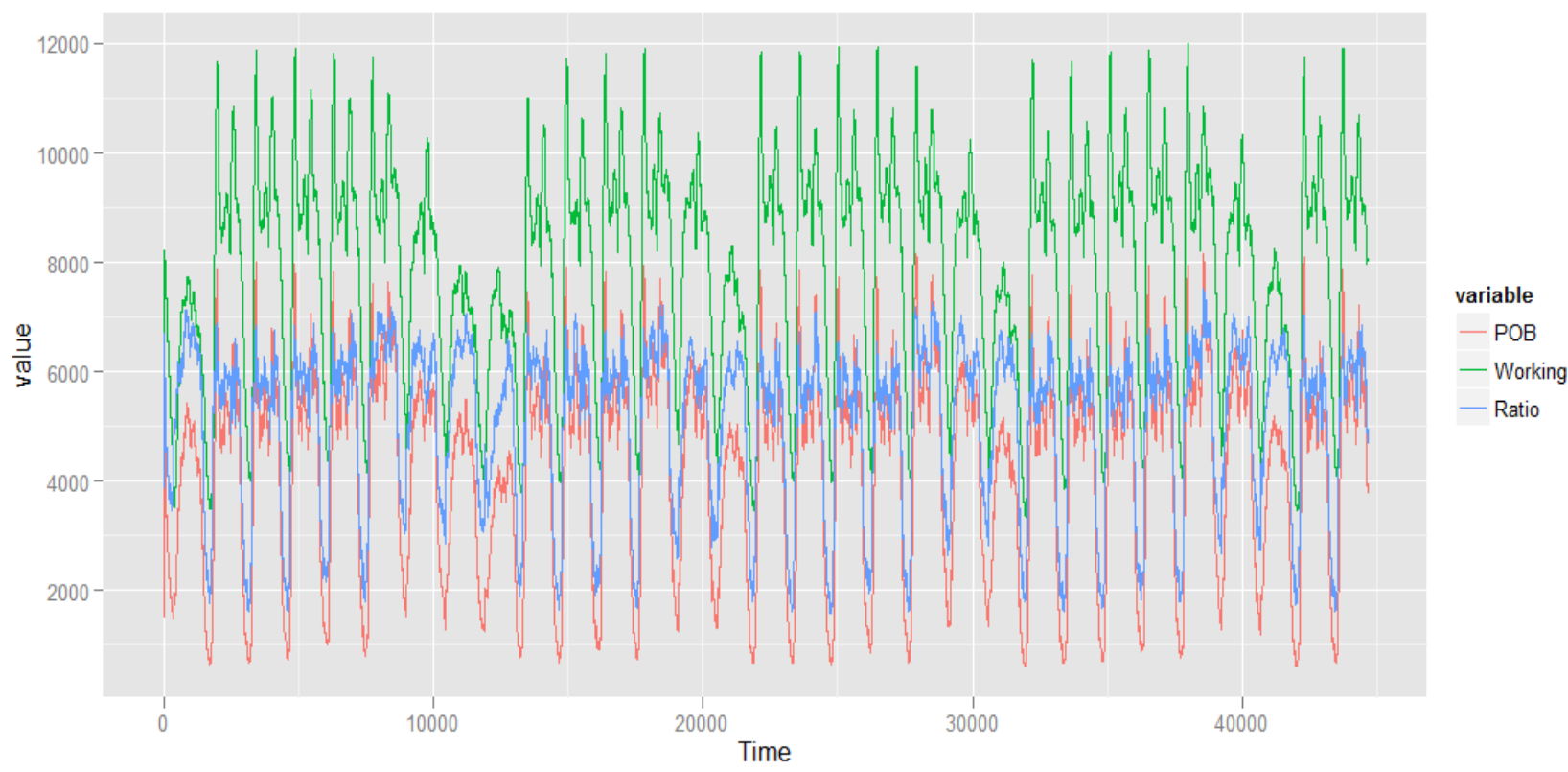

Figure 6: Distributions of Day-by-Day Supply and Demand of Cab Services and Wage Rate for the week from August 15 to 21,2010

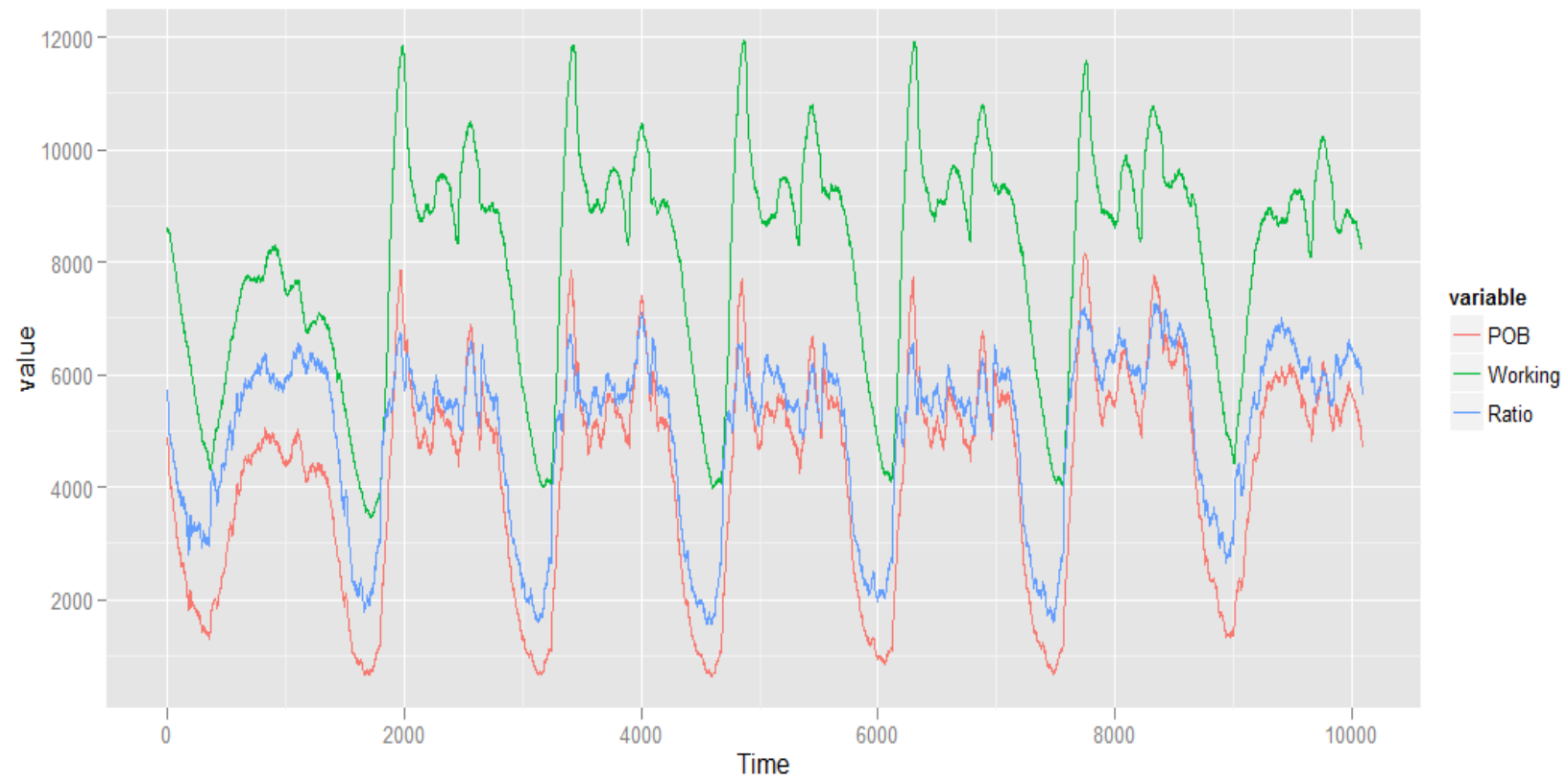


Figure 7: Cabdriver Labor Supply and Demand by day
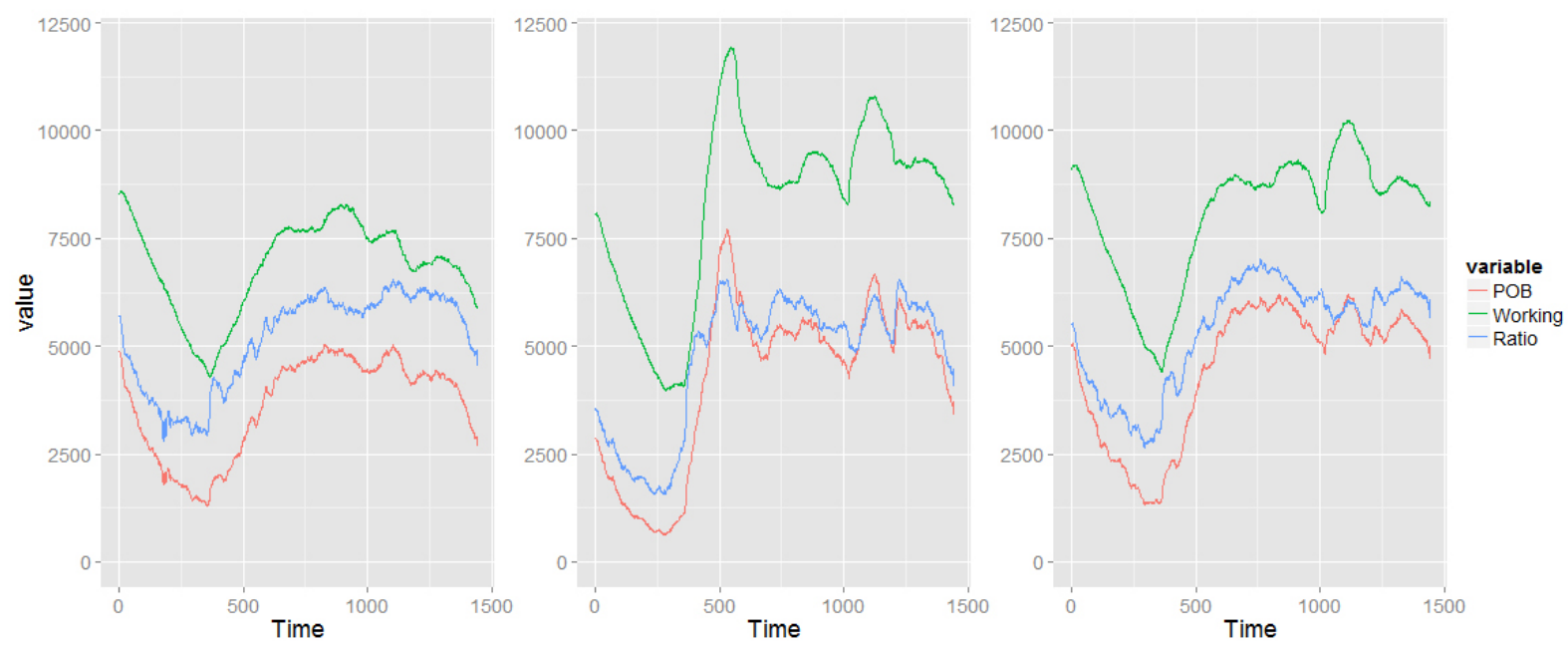
Figure 8: Distributions of Cabdrivers' activities by shift

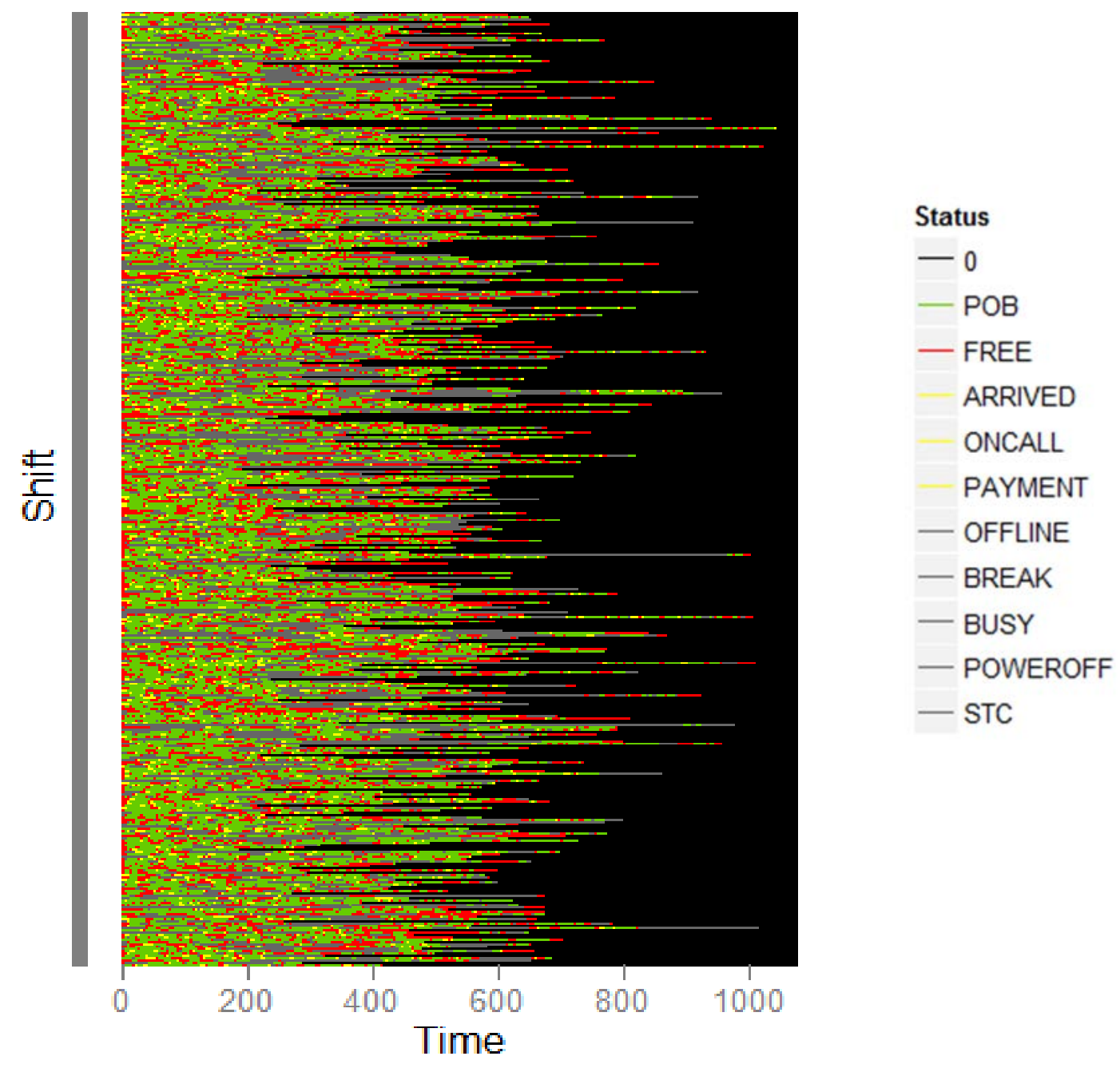

Note: Each line in this chart represents a shift (5000 shifts) 
Figure 9: Cumulative Distributions of Shifts by Cabdrivers for the Month of August 2010

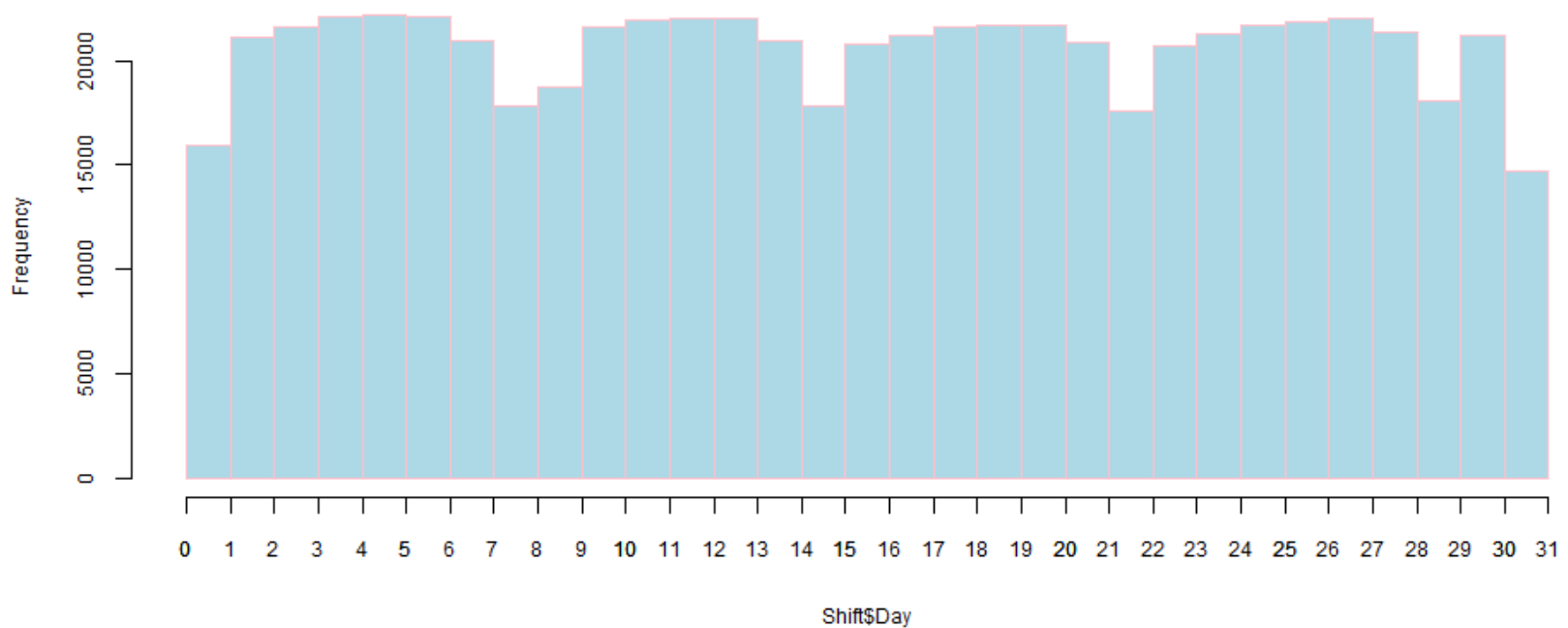


Figure 10: Distribution of Shift Starting time

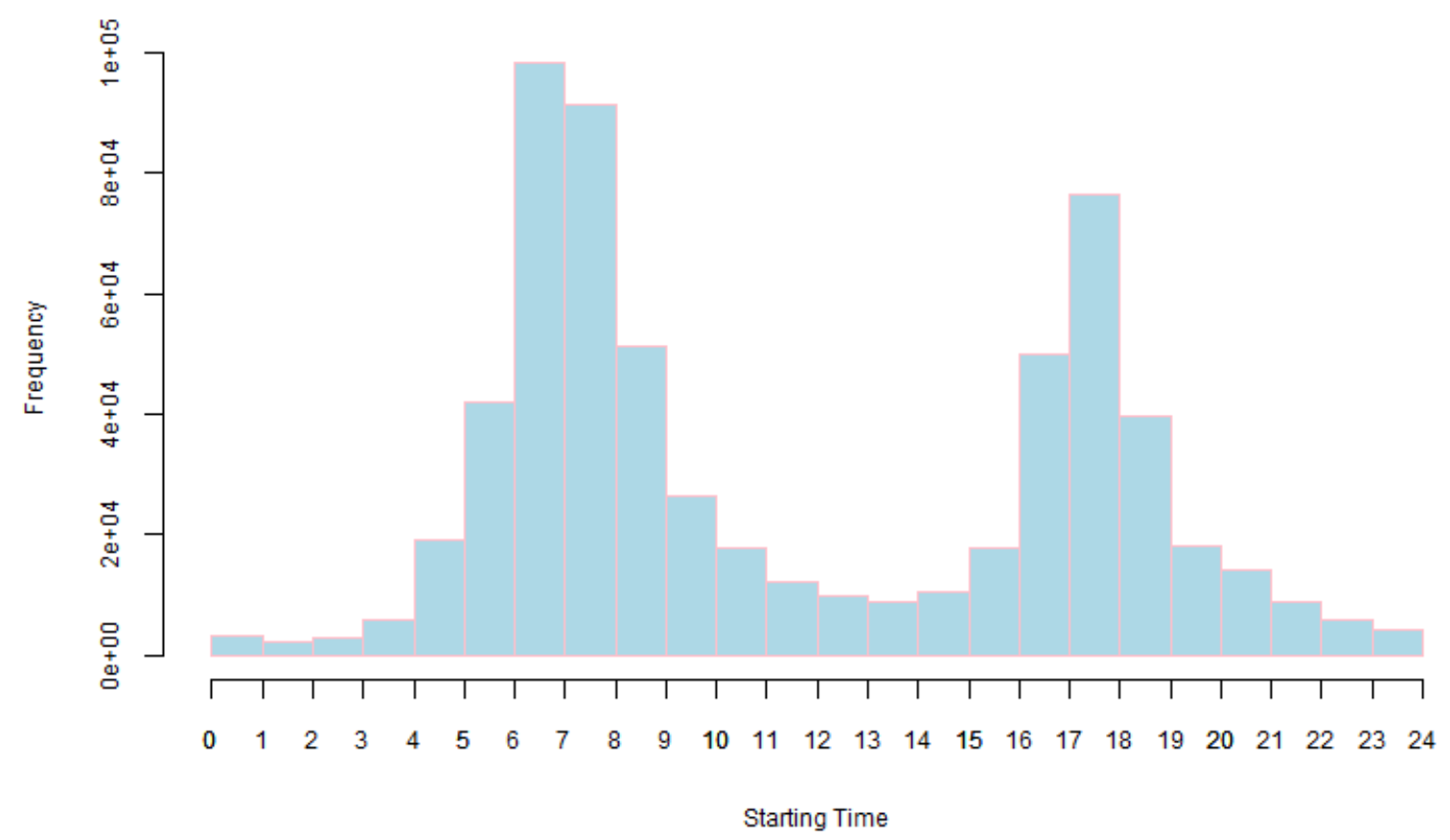


Figure 11: Distributions of Shift Ending Time

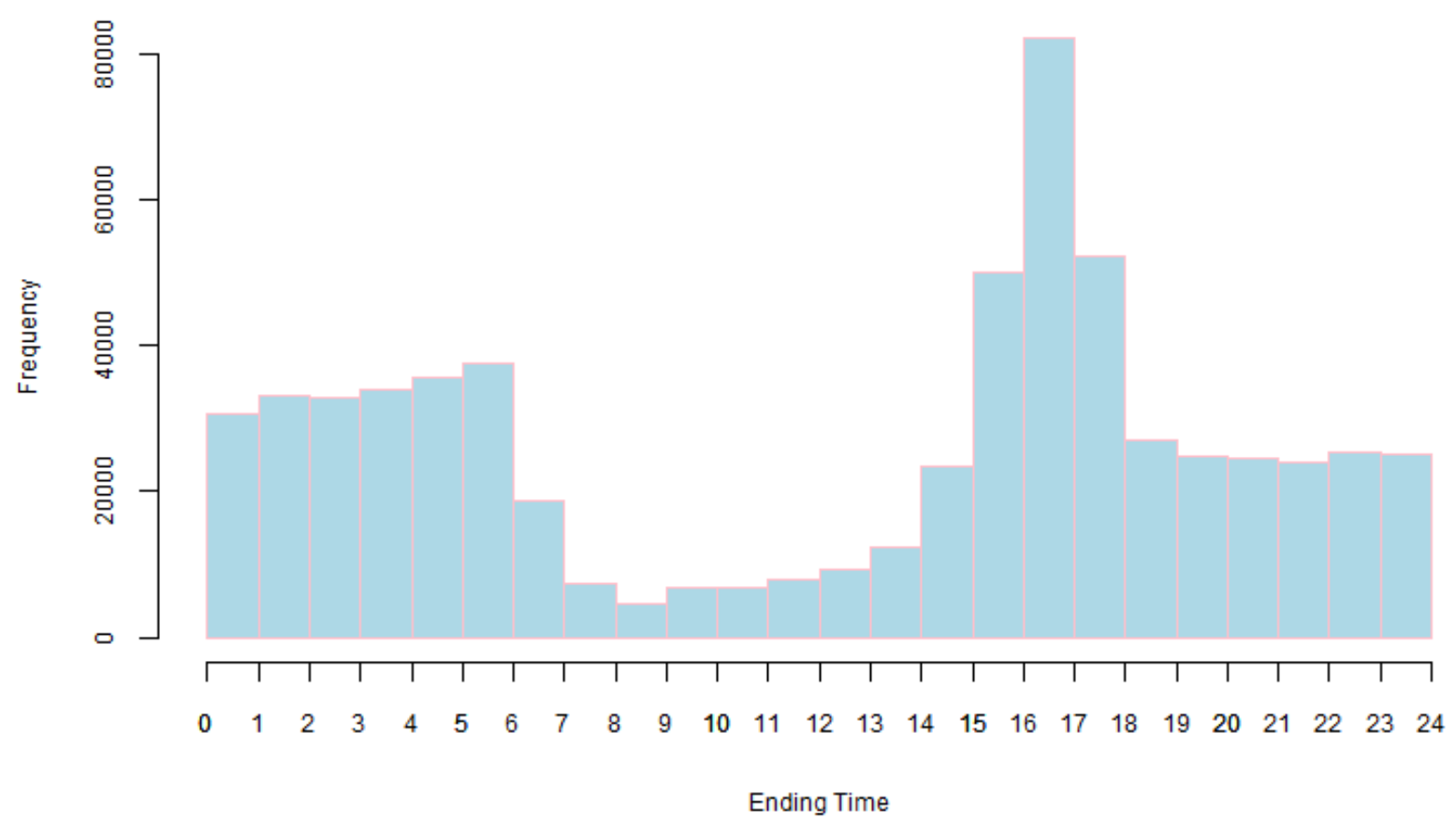


Figure 12: Distribution of Shift Interval (Full Sample) (August 2010)

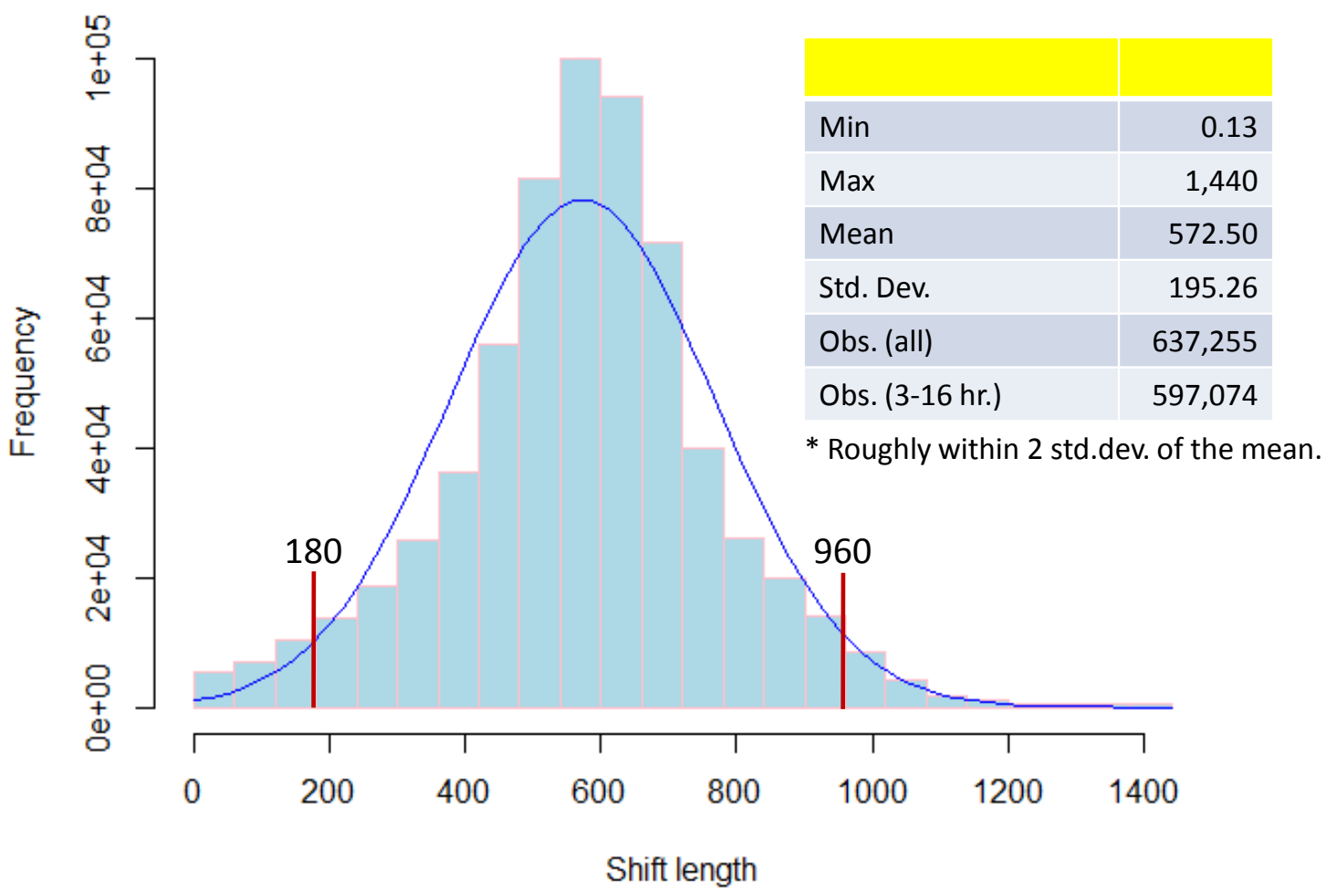


Figure 13: Distributions of Shift interval by active cabdrivers*

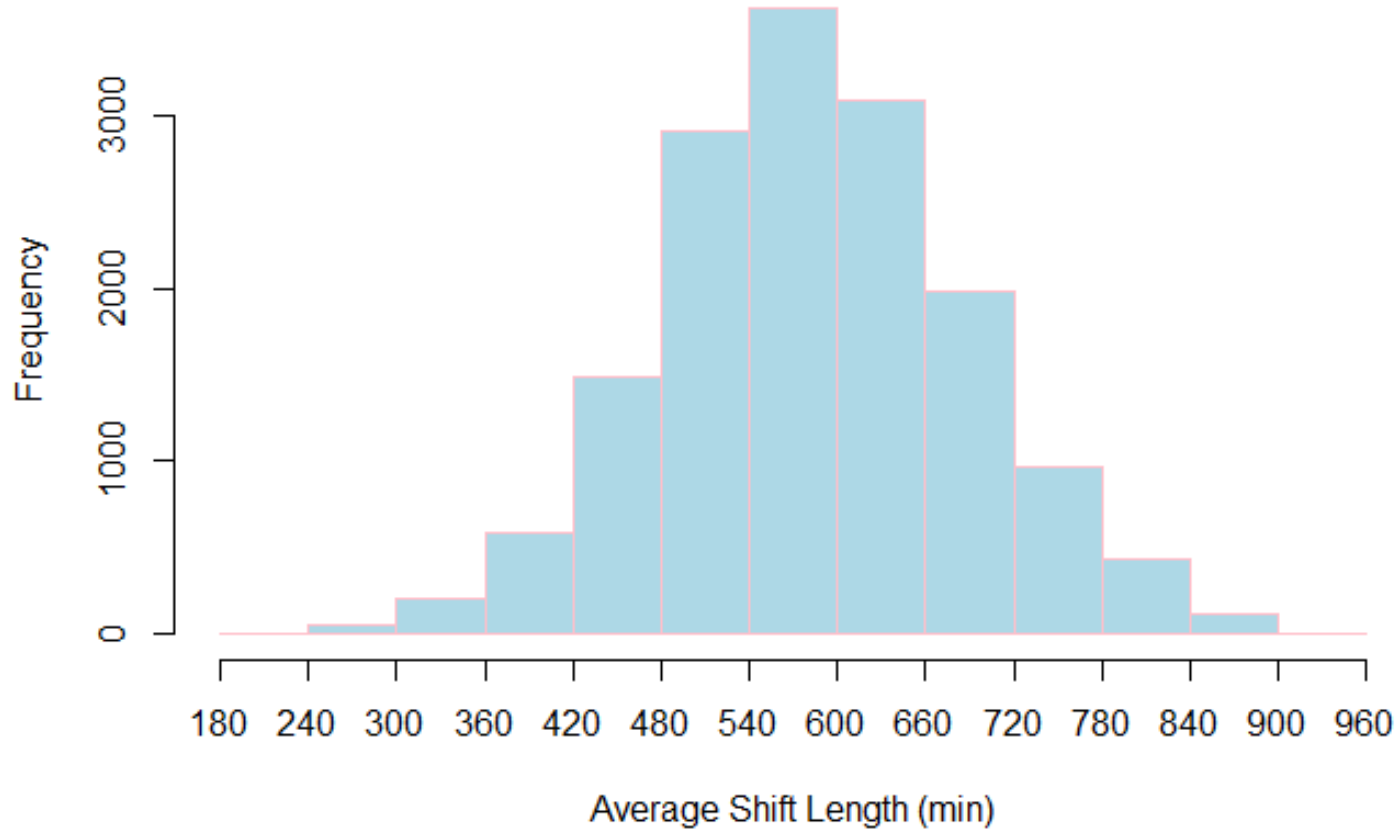

*An active cabdriver is identified as one who drives for a minimum 20 shifts in a month 
Figure 14: Distributions of standard deviations of shift interval by active cabdrivers*

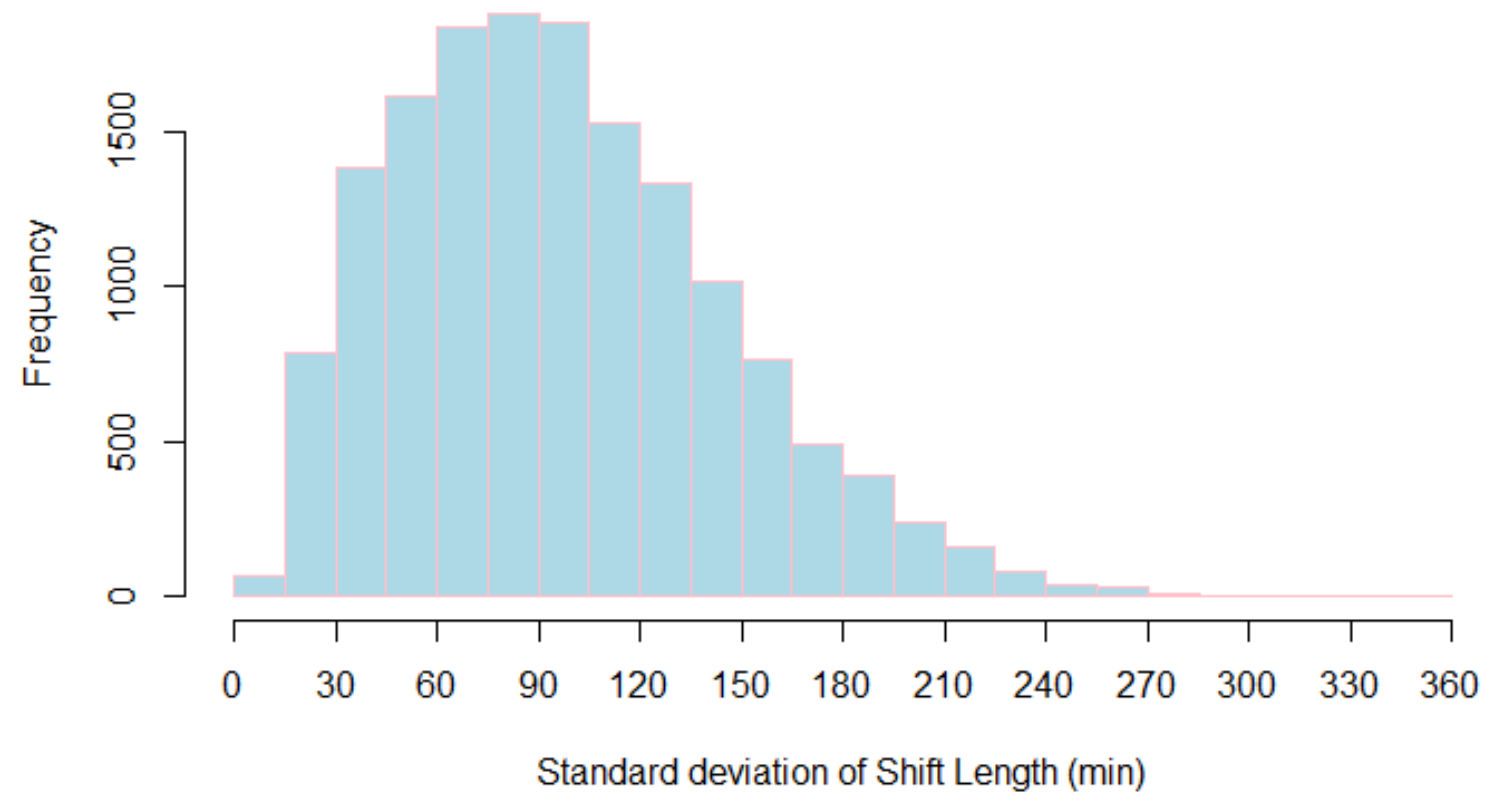

*An active cabdriver is identified as one who drives for a minimum 20 shifts in a month 
Figure 15: Distributions of wage rate of active cabdrivers*

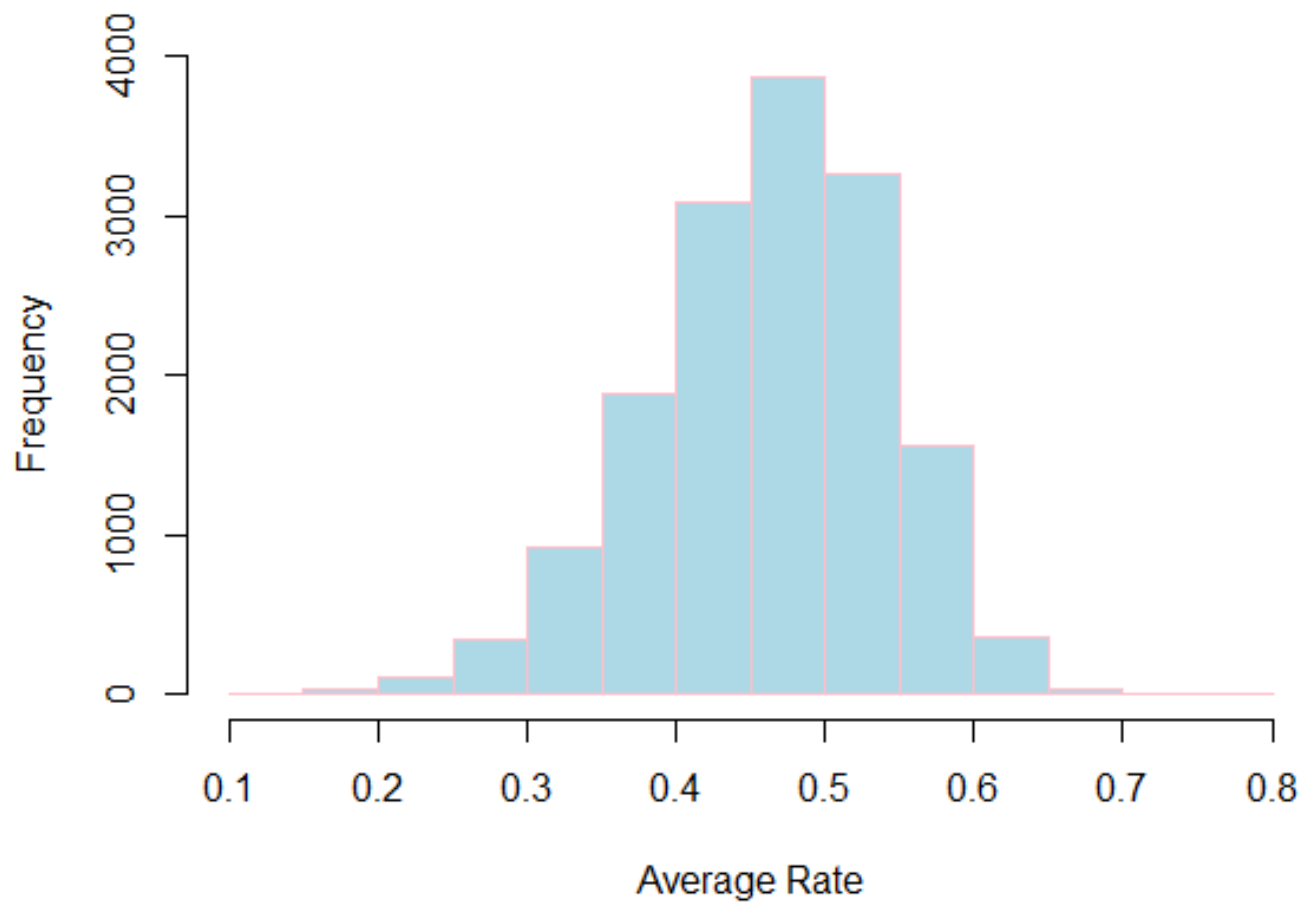

*An active cabdriver is identified as one who drives for a minimum 20 shifts in a month 
Figure 16: Distribution of standard deviations of active cabdrivers*

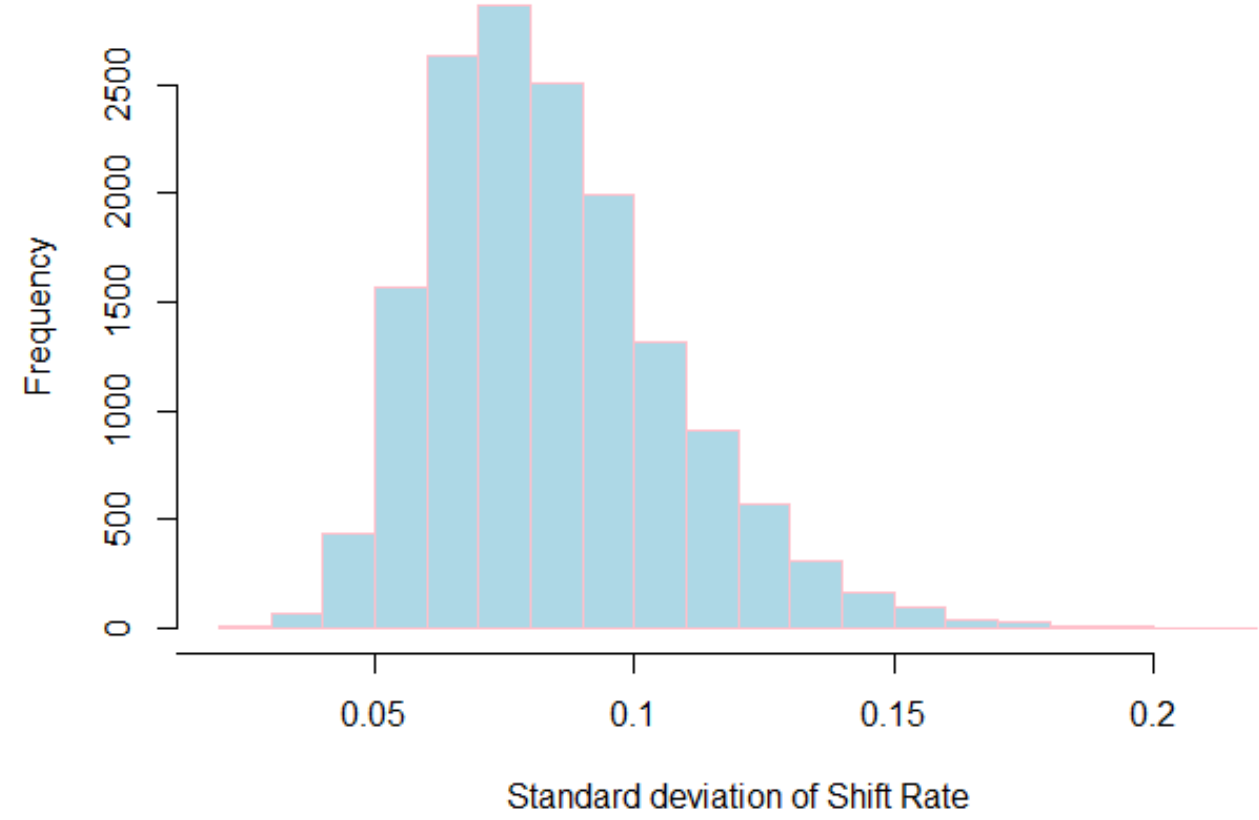

*An active cabdriver is identified as one who drives for a minimum 20 shifts in a month 
Figure 17: Scatter Plot and Local Polynomial Regression Fitting for all Shifts

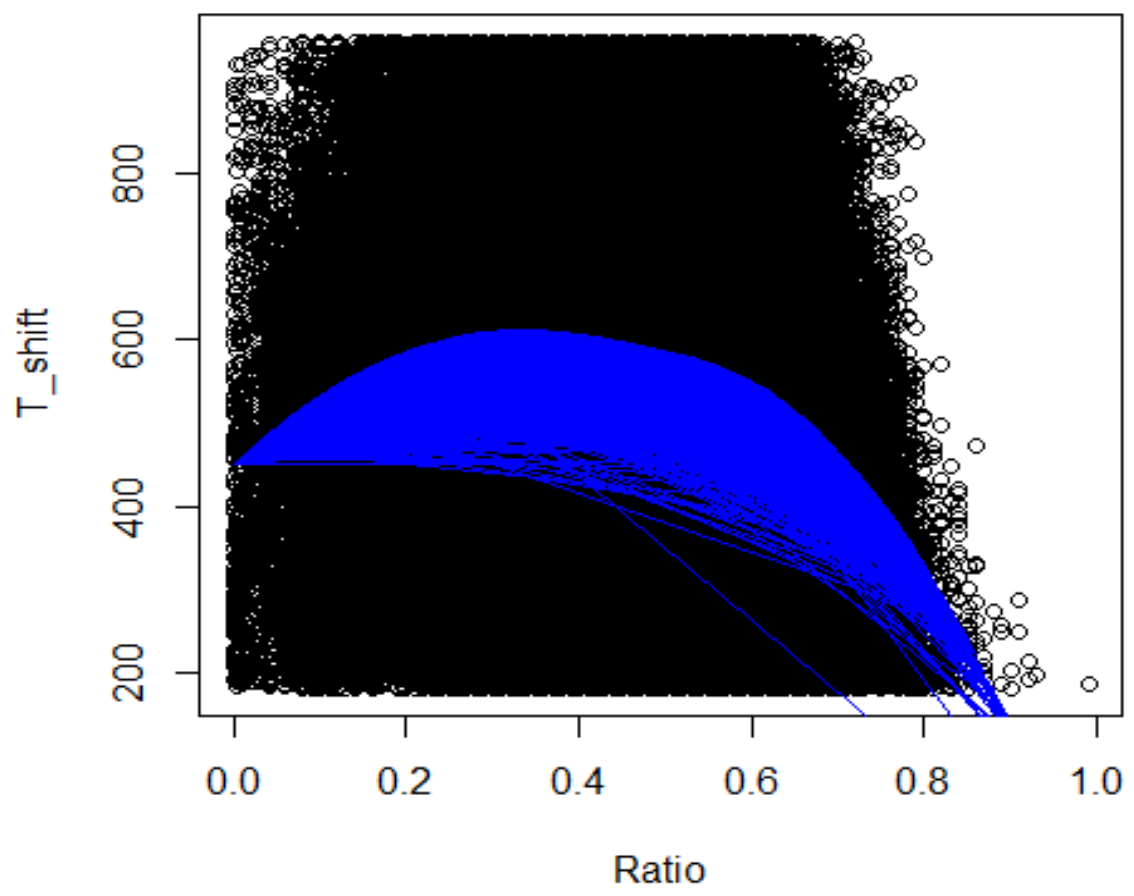


Figure 18: Differences between Single-Shift and Two-Shift Cabdrivers
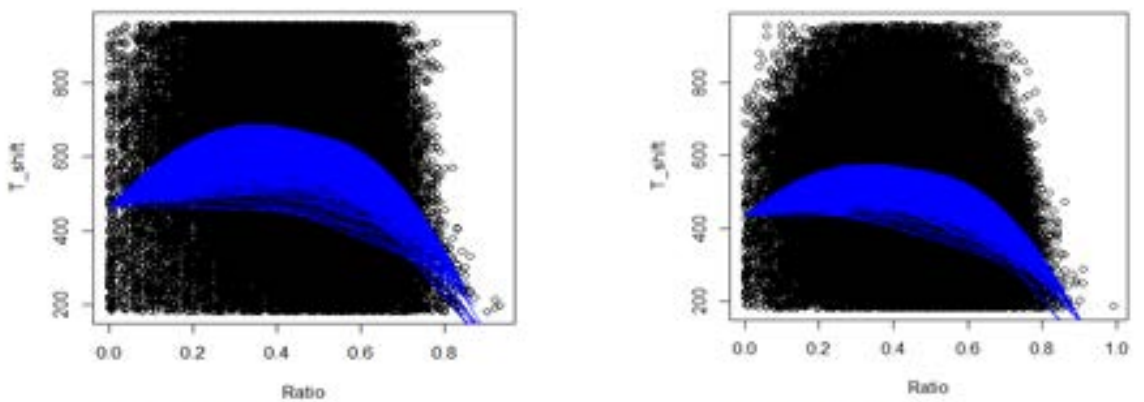

a) Single-shift cabdrivers

b) Two-shift cabdrivers
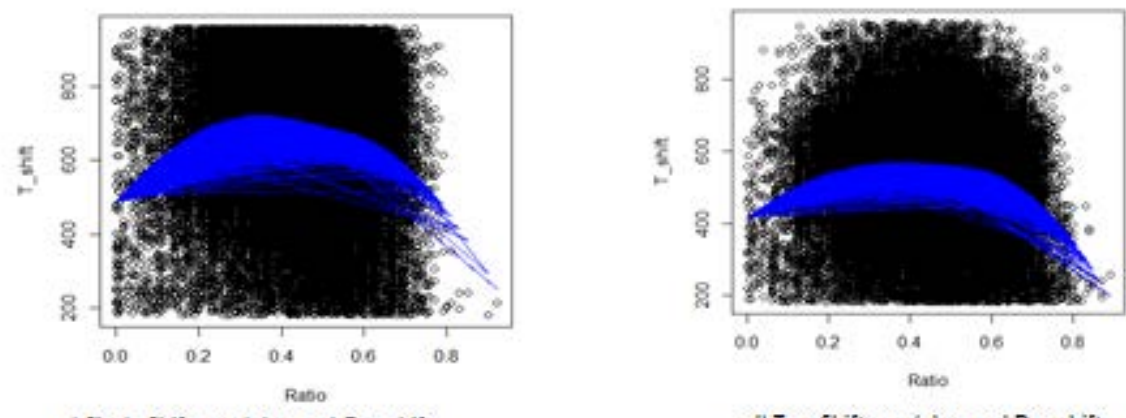

c) Single-Shift, weekday and Day-shift

d) Two-Shift, weekday and Day-shift 
Figure 19: Effects of Rainy Day on Worked hours and Wage Rate Relationships

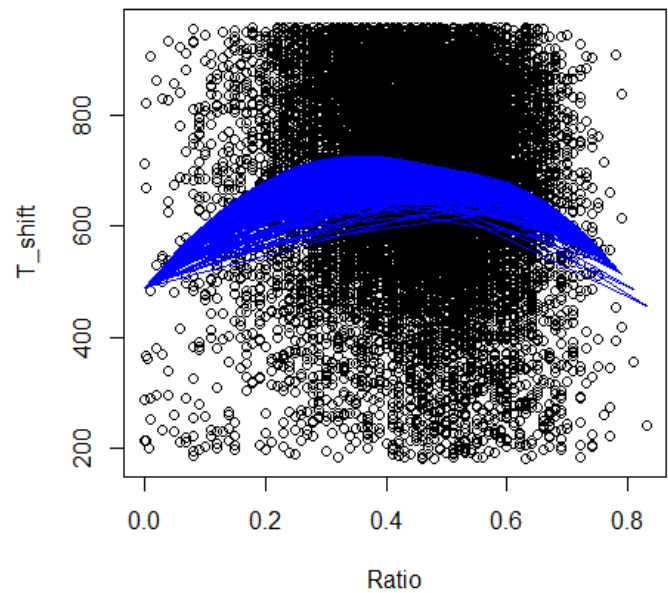

f) Single-shift, weekday, day shift, high rain days

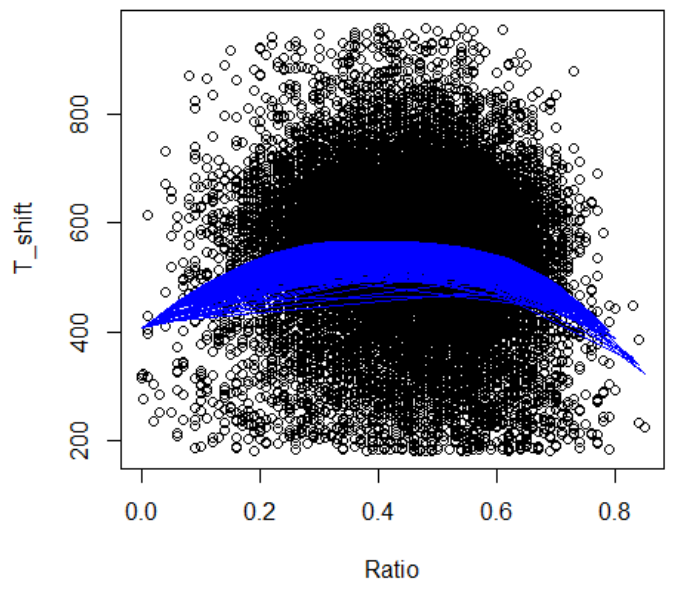

f) Single-shift, weekday, day shift, low rain days

Figure 20: Average Cumulative POB/Working Time by Shift Time (Aug 01-07)

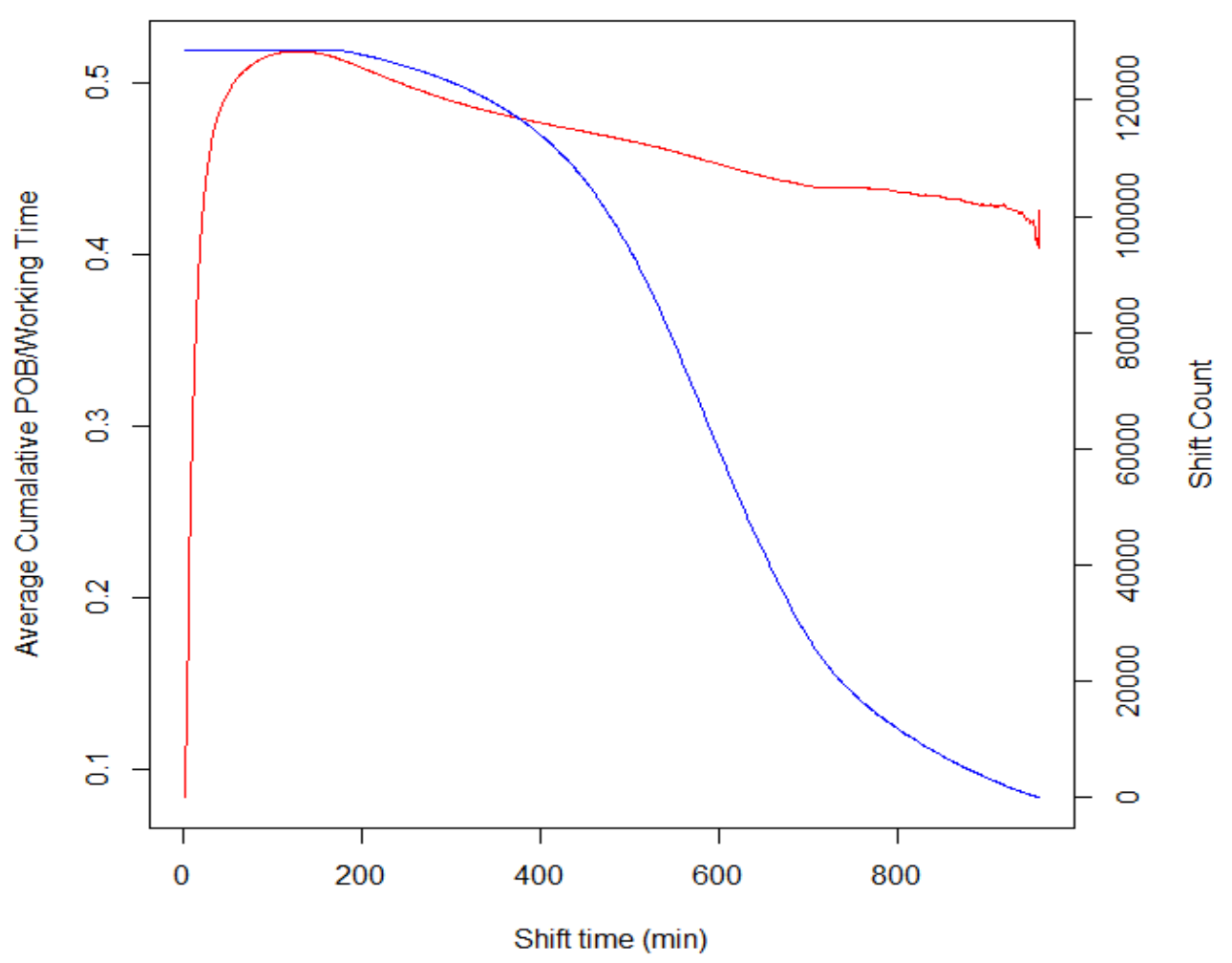




\section{Appendix: Fares and Rates of one of the largest Cab Operators in Singapore}

\begin{tabular}{|c|c|c|c|c|}
\hline \multicolumn{5}{|l|}{ A) Metered Fare ${ }^{\%}$ : } \\
\hline 1. The first $1 \mathrm{~km}$ or less (Flag Down) & $\begin{array}{l}\text { Toyota Crown } \\
\text { Taxis }\end{array}$ & $\begin{array}{l}\text { Hyundai } \\
\text { Sonata Taxis }\end{array}$ & $\begin{array}{l}\text { Toyota Camry } \\
\text { Hybrid Taxis }\end{array}$ & $\begin{array}{l}\text { Hyundai i- } \\
40 \text { Taxis }\end{array}$ \\
\hline & $\begin{array}{l}\text { US\$2.44 } \\
(\mathrm{S} \$ 3.00)\end{array}$ & $\begin{array}{l}\mathrm{US} \$ 2.60 \\
(\mathrm{~S} \$ 3.20)\end{array}$ & $\begin{array}{l}\text { US\$2.76 } \\
\text { (S\$3.40) }\end{array}$ & $\begin{array}{l}\text { US\$2.84 } \\
\text { (S\$3.50) }\end{array}$ \\
\hline 2. Every $400 \mathrm{~m}$ thereafter or less up to $10 \mathrm{~km}$ & & & \multicolumn{2}{|c|}{ US\$0.18 (S\$0.22) } \\
\hline 3. Every $350 \mathrm{~m}$ thereafter or less after $10 \mathrm{~km}$ & & & \multicolumn{2}{|c|}{ US\$0.18 (S\$0.22) } \\
\hline 4. Every 45 seconds of waiting or less* & & & \multicolumn{2}{|c|}{ US\$0.18 (S\$0.22) } \\
\hline
\end{tabular}

\section{B) Booking Charges*:}

1. Current Booking ${ }^{\&}$

$\underline{\text { Peak Period }}$

US\$2.68 (S\$3.30)

Monday to Friday (Except Public Holidays): 6.00am - 9.30am

Monday to Sunday \& Public Holidays: 6.00pm - Midnight

$\underline{\text { All Other Times }}$

US\$1.87 (S\$2.30)

2. Advance Booking\%

US\$6.50 (S\$8.00)

$\&=$ Applicable at the time booking job is confirmed.

$\%=$ Booking to be made at least half an hour in advance.

\section{C) Surcharges:}

1. City Area Surcharge*

Monday to Sunday \& Public Holidays: 5.00pm - Midnight

US\$2.44 (\$3.00)

2. Peak Period Surcharge:

$\underline{\text { Peak Period }}$

Monday to Friday (Except Public Holidays): 6.00am - 9.30am

Monday to Sunday \& Public Holidays: 6.00pm - Midnight

3. Late Night Surcharge:

Midnight - 5.59am

$50 \%$ of metered fare

4. ERP Charge

Passengers are required to bear the ERP charge shown on the upper display of the In-vehicle Unit. The ERP charge is deducted each time the taxi passes under the ERP gantry.

5. Others:

Every trip starting from Changi Airport, Changi Air Freight Centre, Airport Police

Station and Airport Logistics Park of Singapore

- $\quad$ Friday to Sunday (5.00pm - Midnight)

US\$4.06 (S\$5.00)

- All Other Times

US\$2.44 (S\$3.00)

Every trip starting from Marina Bay Cruise Centre Singapore

Monday to Sunday \& Public Holidays (7.00am - 10.59am)

US\$4.06 (S\$5.00)

- $\quad$ All Other Times

US\$2.44 (S\$3.00)

Every trip starting from Seletar Airport and Resorts World Sentosa

US\$2.44 (S\$3.00)

Every trip starting from Singapore Expo Centre

US\$1.63 (S\$2.00)

A surcharge pegged to the prevailing ERP rate is payable by passengers alighting at

Fuji Xerox Towers along Anson Road.

* Applicable at the time of boarding for taxis hired within the City Area and payable on top of the Peak Period Surcharge.

\%Exchange Rate as on May 8, 2013: S\$1.00 to US\$0.81.

Source: http://www.cdgtaxi.com.sg/commuters_services_rates.mvn?cid=2214322 